Article

\title{
Towards Flexible Distribution Systems: Future Adaptive Management Schemes
}

\author{
Hannu Laaksonen ${ }^{1, *(\mathbb{D})}$, Hosna Khajeh ${ }^{1} \mathbb{D}$, Chethan Parthasarathy ${ }^{1} \mathbb{D}$, Miadreza Shafie-khah ${ }^{1}$ and \\ Nikos Hatziargyriou 2 (D) \\ 1 School of Technology and Innovations, Flexible Energy Resources, University of Vaasa, 65100 Vaasa, Finland; \\ hosna.khajeh@uwasa.fi (H.K.); chethan.parthasarathy@uwasa.fi (C.P.); \\ miadreza.shafiekhah@uwasa.fi (M.S.-k.) \\ 2 School of Electrical and Computer Engineering, National Technical University of Athens, \\ 10682 Athens, Greece; nh@power.ece.ntua.gr \\ * Correspondence: hannu.laaksonen@uwasa.fi
}

Citation: Laaksonen, H.; Khajeh, H.; Parthasarathy, C.; Shafie-khah, M.;

Hatziargyriou, N. Towards Flexible Distribution Systems: Future Adaptive Management Schemes. Appl. Sci. 2021, 11, 3709. https:// doi.org/10.3390/app11083709

Academic Editor:

Luis Hernández-Callejo

Received: 19 March 2021

Accepted: 14 April 2021

Published: 20 April 2021

Publisher's Note: MDPI stays neutral with regard to jurisdictional claims in published maps and institutional affiliations.

Copyright: (c) 2021 by the authors. Licensee MDPI, Basel, Switzerland. This article is an open access article distributed under the terms and conditions of the Creative Commons Attribution (CC BY) license (https:// creativecommons.org/licenses/by/ $4.0 /)$.
Abstract: During the ongoing evolution of energy systems toward increasingly flexible, resilient, and digitalized distribution systems, many issues need to be developed. In general, a holistic multi-level systemic view is required on the future enabling technologies, control and management methods, operation and planning principles, regulation as well as market and business models. Increasing integration of intermittent renewable generation and electric vehicles, as well as industry electrification during the evolution, requires a huge amount of flexibility services at multiple time scales and from different voltage levels, resources, and sectors. Active use of distribution networkconnected flexible energy resources for flexibility services provision through new marketplaces will also be needed. Therefore, increased collaboration between system operators in operation and planning of the future power system will also become essential during the evolution. In addition, use of integrated cyber-secure, resilient, cost-efficient, and advanced communication technologies and solutions will be of key importance. This paper describes a potential three-stage evolution path toward fully flexible, resilient, and digitalized electricity distribution networks. A special focus of this paper is the evolution and development of adaptive control and management methods as well as compatible collaborative market schemes that can enable the improved provision of flexibility services by distribution network-connected flexible energy resources for local (distribution system operator) and system-wide (transmission system operator) needs.

Keywords: distributed energy resources; flexibility services; active network management; distribution networks; frequency control; voltage control; flexibility markets

\section{Introduction}

Energy systems are changing due to global drivers related to climate change and environmental issues as well as due to the increasing dependency on electricity. Therefore, there is a need to integrate a large amount of renewable, intermittent wind and solar generation into the energy system, as well as a need to improve the efficiency of the whole system and the reliability and quality of energy supply. However, an increased amount of variable inverter-connected generation also creates challenges and requires more flexibility in the form of flexibility services of different types and sizes of energy resources to fulfill the flexibility needs at different levels of the system. The flexible energy resources, i.e., flexibilities, can consist of distributed generation (DG), energy storages (ESs), demand response, or electric vehicles (EVs). In addition, active $(P)$ and reactive power $(Q)$ control potential of the distribution network (medium-voltage, MV and low-voltage, LV) connected distributed energy resources (DERs), i.e., flexibility must be used increasingly in the future power systems to manage renewables uncertainties and variabilities-related challenges. In addition to large-scale integration of renewables, transportation, and industrial processes, 
large-scale electrification in future energy systems will also increase the need for flexibility and different kinds of energy storage and conversion solutions (electricity, heat, gas/fuel) with different time scales (from milliseconds to months) as well as a new type of solutions to generate electricity again from the stored or converted renewable energy $[1,2]$.

On the other hand, the development and evolution of smart energy systems will enable the energy transition and large-scale integration of renewable energy sources. It also enables improved flexibility, energy, and cost-efficiency as well as sustainability and resiliency of the whole energy system. This can be achieved by use of:

- Advanced cyber-secure information and communications technology (ICT) architectures [3] and interoperable platforms [4] (based on technologies such as 5G/6G, cloud/edge [5] -solutions, new data sources, and data lakes, big data analytics, artificial intelligence (AI), machine learning (ML)) enabling

- Increased sector coupling (electricity, heat, gas, hydrogen, and transportation networks) and

- Integration of different energy storage technologies (battery storages, heat storages, power-to-X-to-power (P2X2P))

- New flexibilities use and sector coupling enabling regulation (legislation, taxation, etc.) and market structures and business models $[1-3,6]$.

Prosumers/households, microgrids, local energy communities, aggregators/flexibility operators, and transmission and distribution system operators (TSOs and DSOs) are some of the key stakeholders in future energy systems. Their simultaneous and sometimes contradicting needs may also increase the system operation and management complexity during the evolution. Therefore, future digitalized protection, control, and management devices and their software must also be flexible, interoperable, cyber-secure, and be easily updated. For these reasons, new types of co-simulation platforms for research and testing [7] will be increasingly needed during the evolution.

A holistic multi-level systemic view is required on the future enabling technologies [1-3], control and management methods, operation and planning principles, regulation as well as market and business models. In this way, the whole energy system costs are minimized, and the collaborative societal and customer value is maximized during the energy system evolution. However, this requires the combination and coordinated use of flexibilities from all voltage levels (LV, MV, and high-voltage, HV) and different energy sectors with different time scales. Digitalization and advanced ICT technologies such as data analytics, AI, and ML as part of future monitoring and management solutions can enable better fulfillment of customers' individual needs and realization of more accurate flexibility forecasts, new energy services, market schemes, and business models.

In this paper, the evolution toward a flexible distribution system is divided into three stages. The evolution during these stages is strongly dependent on the simultaneous power system readiness level (PSRL), which consists of (i) technology/solutions, (ii) customer, (iii) regulation, and (iv) market and business model readiness, as shown in Figure 1.

In order to achieve future flexible and digitalized electricity distribution systems as a key part of the whole power/energy system evolution (stage 3 in Figure 1), simultaneous complementary development of all areas (i)-(iv) (Figure 1) is required. For example, technology/solutions development alone will not enable the evolution. In this paper, however, the main focus is on the development and potential evolution of different technologies and solutions, especially regarding the evolution of DER/distribution network control and management schemes as well as compatible market structures. 


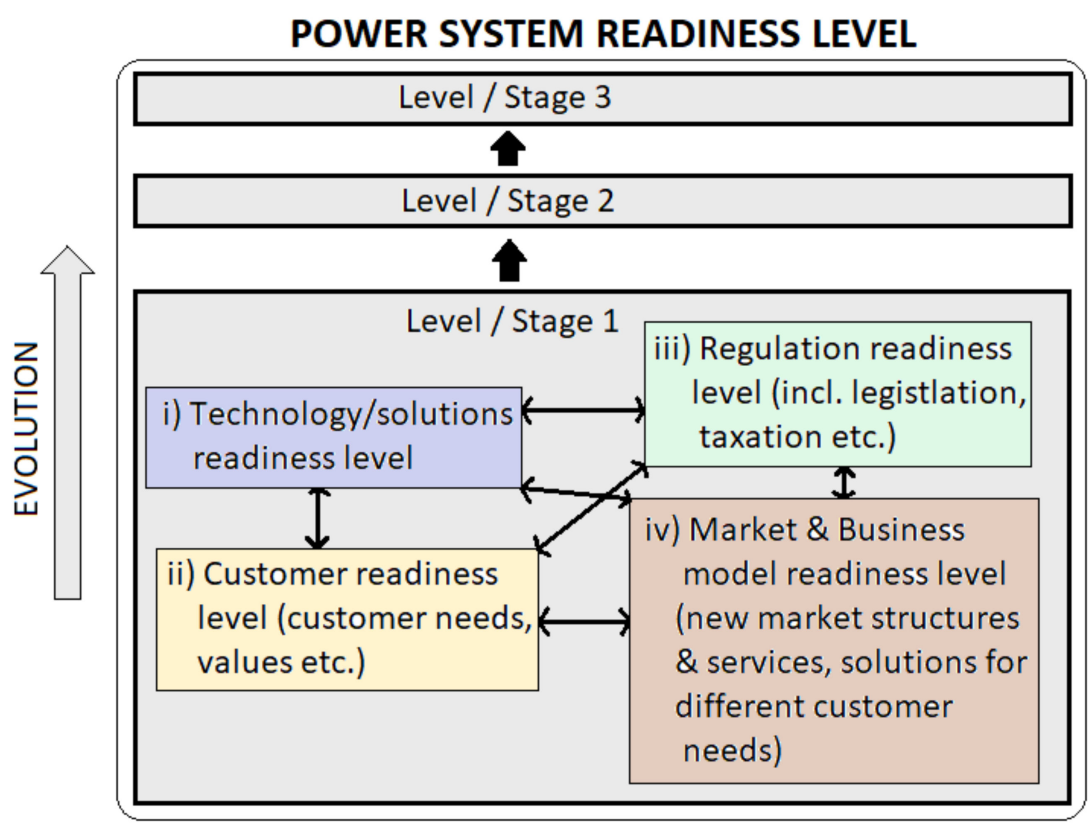

Figure 1. Power system readiness level, PSRL evolution that requires simultaneous development and readiness of (i) technology/solutions, (ii) customer, (iii) regulation, and (iv) market and business models.

At first, Section 2 of this paper describes the potential three-stage evolution path toward fully flexible and digitalized electricity distribution networks. After that, Section 3 presents the potential evolution of future adaptive control and management methods for the improved provision of local and system-wide services by distribution networkconnected flexibilities. The target of these methods is to maximize the availability of all distribution network-connected flexibilities for different DSO and TSO flexibility needs through future market schemes (Section 4). Finally, conclusions are stated in Section 5.

\section{Evolution of Flexible Distribution System}

In order to maximize socio-economic welfare during the evolution of future energy systems, many gaps need to be filled in order to minimize the emissions and costs, to maximize flexibility and resiliency of the whole system, and to provide benefits for participants and stakeholders at different levels of the system.

\subsection{Management Services from Flexible Resources and Communities with Flexibilities}

In the future, DSOs must increasingly enable business opportunities for DERs to provide flexibility services through a marketplace [8,9]. In Europe, recent regulation, i.e., EU electricity market design [10], as well as related electricity market directive [11], also emphasize the important future role of DSOs and consumers/prosumers with DER for the development of flexible distribution systems. In addition, the target is also to solve local challenges locally [1]. Therefore, increased cooperation between DSOs and TSOs [12] is becoming very important in order to maximize the benefits of flexibilities for the whole power system [13]. Future flexibility markets must enable the highest collaborative value of the flexibilities for all stakeholders [14]. Flexibility services for DSOs and TSOs can be related, for example, to (a) frequency control and balancing, (b) congestion management, (c) voltage control, (d) security of supply/islanded (microgrid) operation, (e) reactive power flow control between voltage levels or (f) network losses minimization. However, different options are also possible for the realization of the flexibility services, e.g., (i) technical, (ii) tariff solutions, (iii) market-based, (iv) connection agreement or (v) rule/grid code-based solutions $[8,15]$. 
The location of flexibilities in the power system is highly relevant from the value and local (DSO) and system-wide (TSO) flexibility services point of view. For that reason, forecasted and real-time knowledge about the local need and the availability of flexibilities (active $P$ and reactive $Q$ power) at each voltage or zone level [16] is one key input for active use of flexibilities in the operation and planning of future DSO and TSO networks. In order to ensure maximum availability of flexibilities for different local and system-level services, new adaptive DER and active network management (ANM) principles are needed in order to avoid local flexibilities use restrictions in distribution networks due to congestions related to thermal or voltage limit violations.

Future energy systems will consist of an increased amount of distributed sub-systems with flexible energy resources. These sub-systems can be, for example, energy communities or microgrids. The flexibilities can be used to maximize, for example, household or energy community own benefits and resiliency needs as well as fulfill system operators flexibility and resiliency needs. In this regard, a number of customers could be aggregated and provide various flexibility services for the system operators. For instance, a community of households could help to improve the flexibility of power systems by responding to the network flexibility needs through the use of their controllable appliances. They could also be learned to react according to the different scenarios that can happen for the network, helping to avoid blackouts in emergency situations and improving the power system resiliency simultaneously.

From the optimal and efficient operation of future energy systems viewpoint, it would be of importance that these different local energy communities could also complement each other and simultaneously fulfill the societal, customer, and resiliency needs locally at the community level. Different local energy communities could be, for example, (1) campus local energy communities, (2) urban or rural energy community with households, (3) commercial energy communities, (4) hybrid energy communities, (5) industrial energy communities, or (6) mobile energy communities (such as marine microgrids in ships). Ideally, these different flexible energy resources in different energy communities could complement each other on a daily and weekly basis and participate in different and new market schemes. Energy communities related enabling regulation is required to accelerate their existence.

\subsection{New Operation and Planning Methods for Resilient Digital Distribution Systems}

Future societies will be increasingly dependent on the continuous availability of electricity. Simultaneously, the frequency and intensity of extreme weather events as well as the risk of potential cyber- and physical attacks will also increase. Therefore, the resilience and security of the power system are becoming more critical. Many needed resilience improvements will have to occur on the distribution network/system level. Resilience can be defined as the ability of the system to withstand and reduce the magnitude or duration of disruptive events and rapidly recover from these events in a self-healing manner. This kind of high-impact, low-probability (HILP) event (typically also with sufficiently long duration) can be, for example, due to extreme weather, cyber- and physical attacks, loss of essential data/ICT infrastructure, electromagnetic and geomagnetic disturbances, and fuel security [17].

Future resilient and secure electricity distribution systems should withstand disruptive events and reduce the magnitude and duration of any power failures that do occur. In the future, energy system operation and planning principles must be based on use of flexibilities as well as maximization of system resiliency.

Electricity distribution and transmission network zones with flexible DER and the ability to operate in intended island operation are typical for a definition of a microgrid. Microgrids could be seen as building blocks of future resilient and secure electricity distribution networks. During transmission or distribution network downtimes due to storms, natural disasters, or external attacks (physical or cyber), a microgrid with flexible energy 
resources, such as energy storages, is able to continue electricity supply to customers in islanded operation mode and improve supply security.

On the other hand, the intended microgrid island operation use requires future distribution network control and protection methods to be more active and adaptive. Many of these future control and protection methods will use an increased number of time-synchronized measurements and advanced ICT technologies (such as wireless 5G, cloud, or edge services with big data analytics). Therefore, from a system resiliency viewpoint, aspects related to, for example, cyber-security, reliable time synchronization (e.g., IEEE 1588, synchrophasors, etc.), self-healing and backup power (also for the wireless communication) strategies, redundant low-latency communication solutions as well as local backup solutions (not based on communication) for control and protection will be of key importance.

The future power system management, control, and protection functionalities will be highly dependent on different ICT solutions and the correctness of measured and communicated data. Therefore, cyber-attacks such as false data injection can be considered as an increased risk for secure and stable operation of the power system and the related functionalities. However, false data injection must be distinguished from different power system fault situations as well as false measurements due to measurement errors of faulty measurement devices (e.g., current/voltage sensors or measurement transformers). Different ML- and AI-based techniques also have great potential to be used for these purposes. Resiliency and reliability of the measurements used for protection, control, and management functionalities could be improved, for example, by combined functionalities

- Only communication-based (disconnect/connect) control commands (e.g., for DER control or islanding detection) could be verified before execution by local frequency, voltage and/or other measurements depending on the control command purpose

- For example, participation of DER on system-wide (TSO) frequency control and/or local (DSO) voltage control/congestion management or islanding detection

- Needs information about the control command purpose, i.e., is it based on which parameter(s) can also be verified locally

- Measurements for only local measurements-based functionalities could also be verified before execution by decentralized monitoring schemes in which the feasibility and correctness of the local measurement is checked with one or more nearby measurements

- This would also increase the reliability in false measurements due to damages in measurement devices, etc.

\subsection{Role of Sector Coupling and P2X2P Technologies}

Resiliency can be improved with flexibilities such as storages, but also increased integration of different sectors (electricity, heat, transport, communication) will have an important role. From the resiliency and future distribution network operation and planning viewpoint, for example, locating battery energy storages (BESSs), bi-directional EV fastcharging stations, 5G base stations (for low-latency wireless communication) (a) on the same MV/LV substations at chosen network key locations or b) on EV parking lots with potential photovoltaic (PV) generation, could maximize the flexibilities use potential and resiliency of both distribution network and communication infrastructure (backup power from BESSs and bi-directional EV chargers). In addition, future HV/MV substations could be developed toward sector integration stations with a number of flexible energy resources such as (i) large-scale BESS, EV parking lots with very fast and bi-directional chargers, and hydrogen electrolyzer also producing heat to local heating network or community heat storage. However, regulation development is needed in order to increase coupling between different sectors and energy networks (electricity, heat, hydrogen, natural gas, 
transportation, data/ICT, etc.) [2], e.g., related to taxation energy storages (including also electricity-to-heat-storages and $\mathrm{P} 2 \mathrm{X} 2 \mathrm{P}$-solutions).

Moreover, P2X2P technology can play a key role in improving the flexibility of the distribution network. This technology has already been employed in energy storage devices such as thermal and electrochemical storages. In this regard, the electricity is converted to different types of end-products or other types of energy, and it is converted back to electricity when required. For example, electricity is converted to methanol and methane than can be further used as fuels to produce electricity or other products. Thus, not only can this technology be used as flexible resources, but the obtained alternative carbon-free fuels can also reduce greenhouse gases emission and their negative impacts on the environment. In terms of flexibility enhancement, some projects such as FLEXnCONFU [18] assess the flexibility potential of P2X2P technology. The project aims to design an integrated power plant that improves the operational flexibility of the electrical network. In the first step, electricity is converted into hydrogen $\left(\mathrm{H}_{2}\right)$ or ammonia $\left(\mathrm{NH}_{3}\right)$ when the network has an electricity surplus. These carbon-free fuels are then converted back to electricity when the network needs more electricity injection. Reference [19] also analyses opportunities of the innovative P2X technology regarding Danish wind development and flexibility improvement.

\subsection{Three-Stage Evolution Path toward Flexible and Digitalized Electricity Distribution Systems}

The achievement of future visions $[1,3]$ and the evolution to a flexible electricity distribution system (Figure 2) is divided in this paper into three stages (Table 1). During the evolution, different types of new management $[20,21]$ and market schemes $[15,22-24]$ are needed in order to enable large-scale use of LV and MV network-connected customer flexibilities. The new structures have to be compatible with each other in all evolution stages and act as enablers of the evolution together with new regulation and operation/ planning principles.

Table 1. Potential three-stage evolution path toward fully flexible and digitalized electricity distribution systems/networks.

\begin{tabular}{|c|c|c|c|}
\hline $\begin{array}{l}\text { Development } \\
\text { Stage/Level of }\end{array}$ & $\begin{array}{c}\text { Stage } 1 \\
\text { (Today/Short-Term) }\end{array}$ & $\begin{array}{c}\text { Stage } 2 \\
\text { (Short-/Mid-Term) }\end{array}$ & $\begin{array}{c}\text { Stage } 3 \\
\text { (Mid-/Long-Term) }\end{array}$ \\
\hline (1) Amount of controllable flexibilities & $-/+$ & $++/+++$ & +++ \\
\hline $\begin{array}{l}\text { (2) Accurate forecasting (weather, flexibility, prices, etc. and } \\
\text { multi-timescale: real-time, } 15 \text { min, hour, day, week, month, year) }\end{array}$ & + & $++/+++$ & +++ \\
\hline $\begin{array}{l}\text { (3) TSO flexibility needs (=>new marketplaces and schemes needed, } \\
\text { see 7)) }\end{array}$ & $+/-$ & $++/+$ & $+++/++$ \\
\hline $\begin{array}{l}\text { (4) DSO flexibility needs in distribution networks (e.g., for } \\
\text { congestion management, voltage control, etc.) }\end{array}$ & $+/-$ & $++/+$ & $+++/++$ \\
\hline (5) Required TSO-DSO coordination & - & + & $+++/++$ \\
\hline (6) Coupling between different energy sectors & - & + & $+++/++$ \\
\hline $\begin{array}{l}\text { (7) New market schemes (e.g., local peer-to-peer energy markets } \\
\text { and flexibility markets for small-scale flexibilities) and } \\
\text { products/solutions/services fulfilling individual customer needs } \\
\text { (based on use of AI and data analytics) } \\
\text { (8) Regulation development (related to flexibilities (e.g., BESSs) }\end{array}$ & $+/++$ & $++/+++$ & +++ \\
\hline $\begin{array}{l}\text { use/taxation, energy communities, sector coupling, new market } \\
\text { schemes, etc.) use/taxation, energy communities, and new market } \\
\text { schemes }\end{array}$ & - & ++ & +++ \\
\hline (9) Number of different type of energy communities and microgrids & - & $+/++$ & $++/+++$ \\
\hline (10) Adaptive control and management methods & + & ++ & +++ \\
\hline $\begin{array}{l}\text { (11) Accurate monitoring of distribution networks (i.e., number of } \\
\text { measurements from MV and LV networks for real-time network } \\
\text { state knowledge) }\end{array}$ & - & + & ++ \\
\hline (12) Advanced ICT-based protection and control solutions & - & + & ++ \\
\hline $\begin{array}{l}\text { (13) Operation and planning principles based on flexibilities use } \\
\text { and resiliency maximization }\end{array}$ & $-/+$ & ++ & +++ \\
\hline (14) Resiliency & + & ++ & +++ \\
\hline
\end{tabular}

- (very low/low), + (small/medium), ++ (medium/high), +++ (high/very high). 


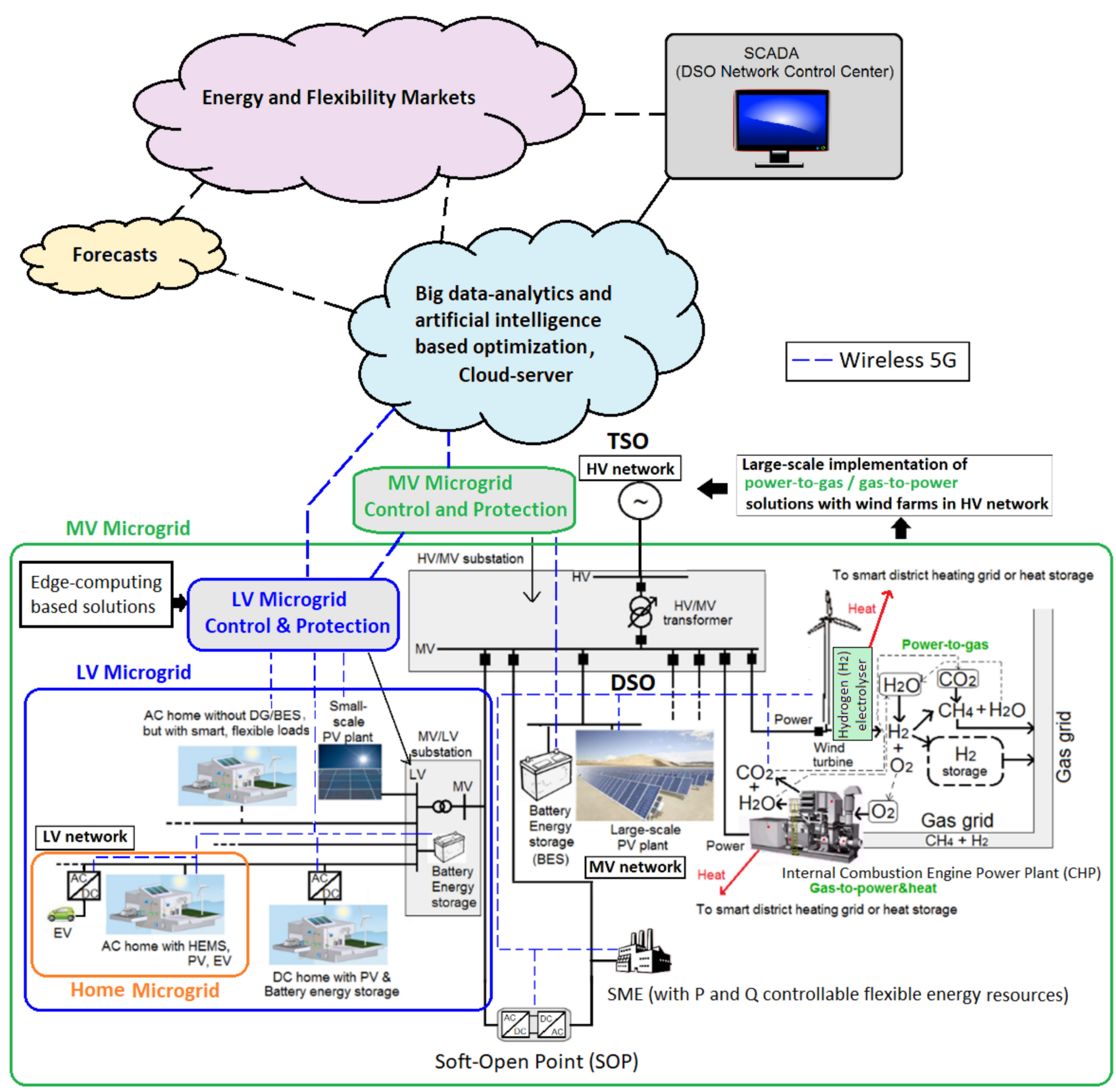

Figure 2. Future flexible and digitalized electricity distribution system.

The evolution stages are dependent on different issues (1-14) and dependencies between them as well as on the level of the existence/deployment of these matters (Tables 1 and 2 and Figure 3). In this paper, the focus is on the evolution and development of adaptive control and management methods. Therefore, in Table 2, the potential evolution of (10) adaptive control and management methods, (11) accurate monitoring of distribution networks, and (12) advanced ICT-based protection and control solutions during stages 1-3 (see Table 1) is described as an example with more details. 
Table 2. The evolution of (10) adaptive control and management methods, (11) accurate monitoring of distribution networks, and (12) advanced ICT-based protection and control solutions during stages 1-3 (see Table 1 and Figure 2).

\begin{tabular}{|c|c|c|c|}
\hline Stage & $\begin{array}{c}\text { Adaptive Control and Management } \\
\text { Methods }\end{array}$ & $\begin{array}{l}\text { Accurate Monitoring of } \\
\text { Distribution Networks }\end{array}$ & $\begin{array}{l}\text { Advanced ICT-Based Protection and } \\
\text { Control Solutions }\end{array}$ \\
\hline 1 & $\begin{array}{l}\text { - ANM is not very commonly } \\
\text { used, only in MV networks with } \\
\text { a large amount of DER } \\
\text { Management system can be } \\
\text { centralized, distributed (local), } \\
\text { or a combination of centralized } \\
\text { and distributed in a coordinated } \\
\text { way } \\
\text { Requirements such as } \\
\text { communication latency may } \\
\text { depend on the application and } \\
\text { provided flexibility service (for } \\
\text { local DSO needs or for TSO } \\
\text { needs) }\end{array}$ & $\begin{array}{l}\text { Level of distribution network } \\
\text { accurate monitoring and } \\
\text { number of measurements from } \\
\text { MV and LV network is low }\end{array}$ & $\begin{array}{l}\text { Traditional protection approach } \\
\text { with separate IEDs, use of IEC } \\
61850 \text { communication standard } \\
\text { and IEEE } 1588 \text { time } \\
\text { synchronization } \\
\text { Only some piloting performed } \\
\text { with centralized protection } \\
\text { solutions and wireless low-latency } \\
\text { 5G-based line differential } \\
\text { protection }\end{array}$ \\
\hline 2 & 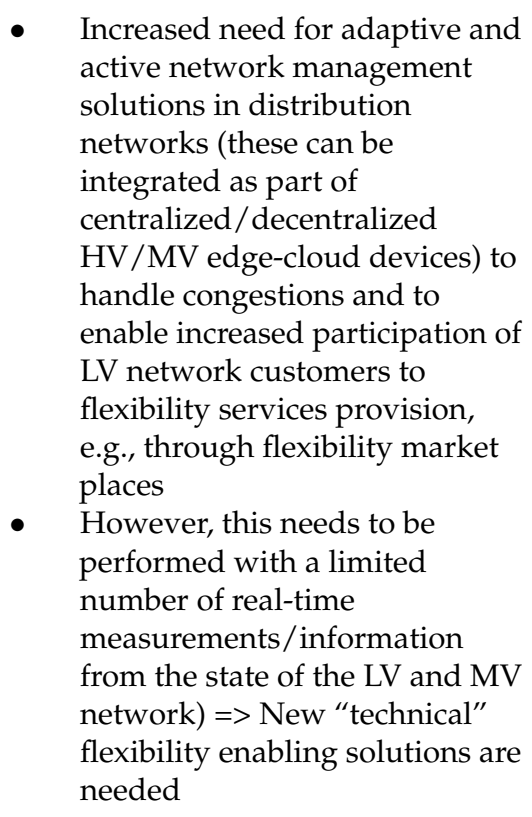 & $\begin{array}{l}\text { - Limited number of } \\
\text { measurements from MV and LV } \\
\text { networks for better real-time } \\
\text { estimation about the state of the } \\
\text { network (use of a low amount of } \\
\text { accurate measurements from } \\
\text { MV/LV substations and LV } \\
\text { network customer connection } \\
\text { points) } \\
\text { Enables also more accurate } \\
\text { monitoring of power quality } \\
\text { parameters and their } \\
\text { development trends from } \\
\text { chosen locations for proactive } \\
\text { protection/developing fault } \\
\text { detection functionalities) }\end{array}$ & $\begin{array}{l}\text { - Fully digital edge-cloud based } \\
\text { centralized devices on new } \\
\text { HV/MV substations for primary } \\
\text { protection (MV) and } \\
\text { control/management } \\
\text { functionalities based on IEC } \\
61850 \text { and IEEE } 1588 \text { for time } \\
\text { synchronization with 5G, } \\
\text { increased amount of } \\
\text { communication-based protection } \\
\text { schemes (differential protection, } \\
\text { islanding detection, etc.), also } \\
\text { using measurements from MV /LV } \\
\text { substations, some use of } \\
\text { PMU/micro-PMU functionalities, } \\
\text { e.g., in distribution networks, } \\
\text { traditional protection relays/IEDs } \\
\text { with local measurements used as a } \\
\text { backup at HV/MV substation }\end{array}$ \\
\hline 3 & $\begin{array}{l}\text { Very high need for compatible, } \\
\text { flexibilities use enabling } \\
\text { technical ANM and intended } \\
\text { (microgrid) island operation } \\
\text { solutions in distribution } \\
\text { networks }\end{array}$ & $\begin{array}{l}\text { High number of measurements } \\
\text { from MV and LV networks for } \\
\text { accurate real-time state } \\
\text { knowledge } \\
\text { AI and ML and satellite } \\
\text { data-based solutions to system } \\
\text { state-monitoring and fault } \\
\text { prediction }\end{array}$ & $\begin{array}{l}\text { - } \\
\text { edge-cloud based } \\
\text { centralized/decentralized devices } \\
\text { from different vendors at } \mathrm{HV} / \mathrm{MV} \\
\text { substations and also at MV/LV } \\
\text { substations with integrated } \\
\text { microgrid management system } \\
\text { functionalities (but without } \\
\text { redundancy or redundancy in } \\
\mathrm{HV} / \mathrm{MV} \text { level edge device) }\end{array}$ \\
\hline
\end{tabular}

\section{Future Adaptive Control and Management Methods}

Future adaptive management methods and compatible flexibility market structures should enable the highest collaborative value of the flexibilities for different stakeholders. From this viewpoint, the location of flexibilities is very important, and it affects, for example, the most feasible use cases and potential restrictions for use of DSO network-connected flexibilities. For instance, the unnecessary transfer of reactive power in distribution networks increases losses and reduces the active power transfer capacity of the lines. In [25], 
it was suggested to a) use DSO network-connected reactive power resources, which are located close to HV / MV substation to control reactive power flow between MV (DSO) and HV (TSO) networks instead of resources located far away from the HV network connection point (e.g., in LV network) and (b) use reactive power resources connected deeper in the MV or LV network for the provision of local (DSO) flexibility services such as congestion management (thermal capacity) and voltage control.

In the use of multiple small-scale, DSO network-connected flexibilities, potential challenges can also be identified. For example, available flexibility may be restricted on three levels:

1. Distribution network-related limitations (voltage level, thermal capacity of lines and transformers) may affect the capability to participate in system-wide markets (weather, time of day, and year dependent),

2. Household/building/shopping mall/office building, etc. specific customer-related limitations (due to temperature, air-quality, day-light, i.e., dependent on weather and time of day and individual behavior or preferences), e.g., [26] and

3. Local optimization (economical, reliability) targets, for example, microgrid or energy community [27] related limitations. For example, non-linear mathematical models of flexible resources increase the complexity of the optimization problem. In addition, stochasticity can adversely affect the optimal operating points of flexible resources.

Risk level should also be considered, i.e., what is the certainty that the offered flexibility can be provided as promised/planned? In general, it can be assumed that urban area flexibilities could be typically restricted by (1) thermal capacity limits as well as (2) customer uncertain behavior and preferences. Correspondingly, in the rural area, flexibilities could be typically restricted by (1) voltage and thermal limits and (2) customer preferences as well as (3) potential local community-related targets in some areas. However, it must be noted that future price signals related to the future market structures (energy, flexibility/ancillary service, and local markets) with dynamic pricing as well as potential dynamic distribution network tariffs, can have a substantial effect on customers' and energy communities' behavior in terms of flexibility services offerings. From the DSOs' viewpoint, a new regulation is needed to enable enhanced use of DER flexibility services as a non-wire alternative and to avoid building excessive new line and transformer capacity [28-32].

Conflict of interest between DSO and TSO regarding use of flexibility services from distribution network-connected resources should be avoided by proper TSO-DSO coordination [12,33-39] and advanced state-monitoring [40] as well as state-forecasting [41,42] in DSO networks. A conflict of interest between DSO and TSO interest has also been observed in real-life pilots, such as in [43]. However, in [43], most of the time, the flexibility needs between DSO and TSO did not have mutual effects, and sometimes the flexibility needs were also in the same direction. In addition to increased TSO-DSO coordination and collaboration in operation, cooperation will be increasingly needed already in the planning [44] stage. Due to different changes, such as increased DER, in the future, more focus must be on control, and estimation [45] of reactive power flows between HV (TSO) and MV (DSO) networks. This is also needed if dedicated markets for reactive power [46-49] will be created. Improved TSO-DSO collaboration enabling new functionalities, flexibility platforms, and marketplaces will be of key importance to foster the evolution and development of future distribution networks [28,50-58].

In the future, improved forecasting (weather, active and reactive power of generation/storage/load/EV, available/needed flexibility, market prices, network state, and $P Q$ flows between voltage levels, etc.) will be an essential part of different management and market schemes enabling flexibility services improved use and provision for DSOs and TSOs. Advanced ICT technologies such as AI- and ML-based data analytics will be needed to create more accurate forecasts for optimal operation of future DSO networks [59-62].

Simultaneous control of multiple small-scale DER units (flexibilities) also requires new standards and guidelines. Therefore, new reference control methods [63], and standards and guidelines for DER aggregation [64], communication, and group management are 
developed and are also constantly under development. These are important from the point of view of the DER units' flexibility services provision and flexibility market participation. New practices and architectures for TSO-DSO data exchange are also needed [65]. Related to reactive power flow control between voltage levels, control stability challenges and oscillations are possible [66], and the control functions operation should be tested, for example, in a real-time simulation environment before field installations.

Different active power $P$ and reactive power $Q$ related flexibility services from the DER units' can be realized by various inverter local control modes, such as constant power factor $(\cos \phi)$, fixed $Q, Q(P), \cos \phi(P), Q U / V o l t-V A r, P U$ and $P f$, where $f$ is the frequency and $U$ is voltage. $Q U$-droop control mode has been typically used with inverter-based DG units connected in distribution networks $[67,68]$. In order to avoid, for example, distribution network-connected PV unit active power $P$ unnecessary curtailment, $Q U$ droop is used as a primary local voltage control method and $P$ curtailment related $P U$-droop as a secondary method. In order to achieve simultaneously the best possible voltage level control in both MV and LV networks, the distribution system connected DER units' voltage control settings, and principles need to be coordinated with, for example, the HV/MV substation on-load tap changer (OLTC) settings. In order to achieve more optimized operation and further improve DG, such as PV, hosting capacity in distribution networks, reduce network losses [69-72], and enable frequency or voltage control participation, etc., enhanced state estimation and coordinated operation is required [73-77]. Already a low level of communication between DER units could enable the achievement of better control settings and improved performance [78]. In the future, in addition to $P$ - and $Q$-controlbased flexibility services, DER units (Figure 3) could also provide other local power quality improvement-related services for DSOs. Such services could be, for example, compensation of unbalance (current and voltage) between three phases as well as compensation of current and voltage harmonics which are expected to increase in LV networks in the future, e.g., due to increased EV and PV integration.

In the following, flexible and adaptive technical management solutions considered in this paper for distribution network-connected flexibilities improved use for local and system-wide services are shown in Figure 3. The target of these new adaptive control and management methods is to maximize the availability of all LV network-connected flexibilities for different DSO and TSO needs during the evolution (Table 1). These proposed adaptive technical management solutions can be seen as flexibility services, and they should be also considered as part of future collaborative TSO-DSO market schemes.

The main principles and settings proposed in Figure 3 are today/in stage 1 (Table 1) decentralized/local and in the near future could be used without or with minimum communication. However, in the future/stages 2-3 (Table 1), increased use of real-time measurements from the MV and LV network with some centralized ANM functions and active participation on different markets and marketplaces will also require increased use of reliable, cost-efficient, low-latency communication. In the future, when more real-time measurements will become available for accurate state estimation and related ANM functions, the setting values of OLTCs and DER unit local QU- and PU-droops could also be more frequently adapted. This means that short- (time of day) forecasts and locational aspects would be increasingly considered with some combined centralized/decentralized multiobjective ANM functionality. Adaptive and flexible $Q U-, P U$ - and $P f$-droop functions could enable local operation optimization at the DSO level by updating the dead-zone values and activation limits of droop functions in a (a) seasonal/monthly/weekly/daily manner (stage 1-2) and (b) a more real-time manner (stage 2-3) [79]. Advanced ICT (5/6G wireless communication and edge computing-based solutions) in stage 2-3 could also enable increasingly decentralized/combined (centralized+decentralized/supervised decentralized) solutions, e.g., at the secondary substation level as well as different local energy and flexibility (peer-to-peer) market schemes. 
Partly based on the conclusions from the previous studies in $[25,80,81]$, adaptive control and management methods evolution to enable increased TSO-DSO collaboration at different stages $1-3$ is presented in Tables $2-5$.

In the following Sections 3.1-3.4, some chosen proposed future adaptive control and management methods at certain evolution stages (Tables 2-5) are presented in more detail.
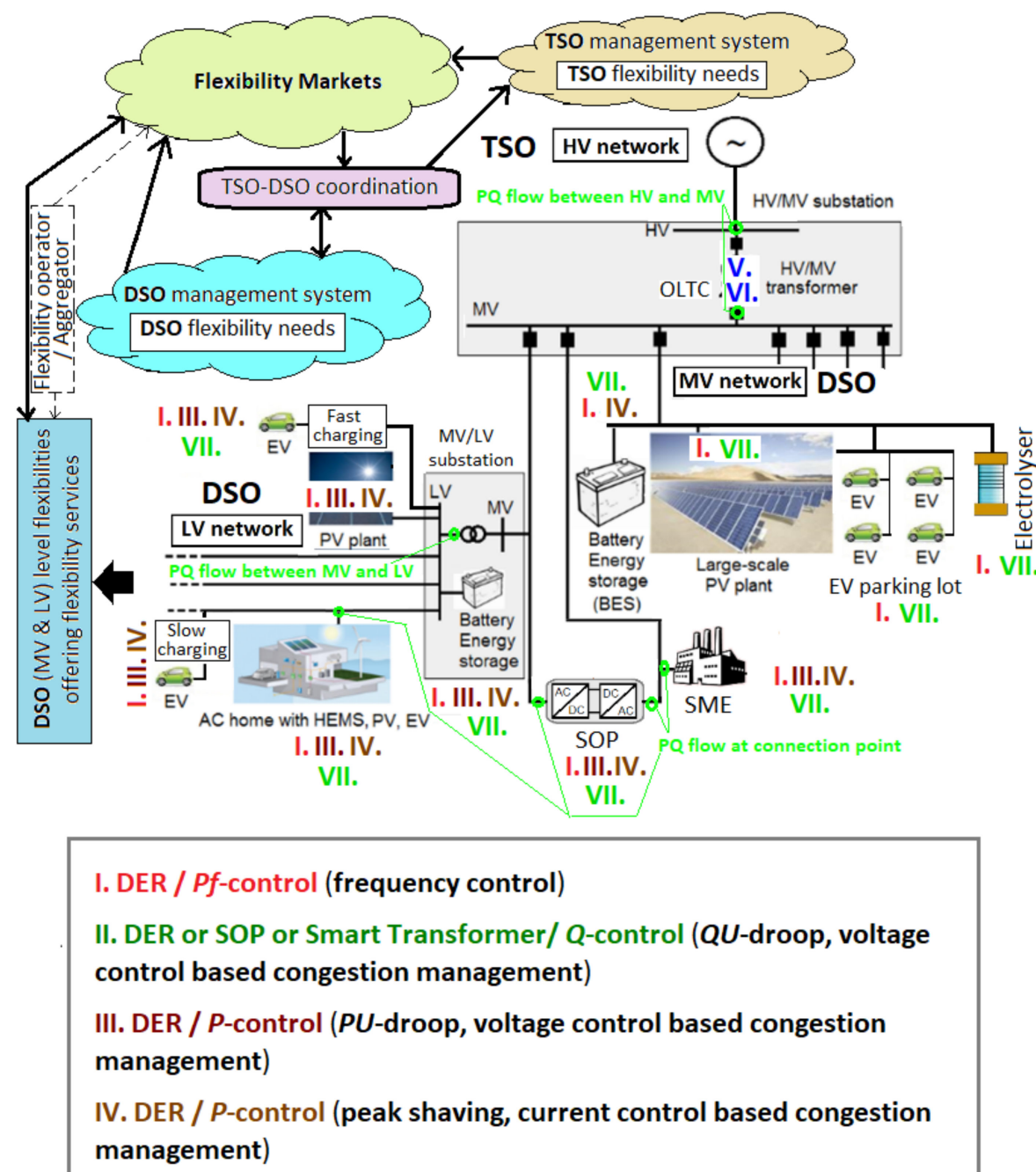

Figure 3. Future adaptive control and management methods to increase flexibility availability for provision of services (see Tables 1-5). 
Table 3. Adaptive control and management methods I.-IV. evolution during different stages 1-3 (see Figure 3, Tables 4 and 5).

\begin{tabular}{|c|c|c|c|c|c|c|c|}
\hline \multicolumn{8}{|c|}{ Adaptive Control and Management Methods } \\
\hline Stage & \multicolumn{2}{|c|}{$\begin{array}{l}\text { I. DER/Pf-Control } \\
\text { (Frequency Control) }\end{array}$} & \multicolumn{2}{|c|}{$\begin{array}{l}\text { II. DER/Q-Control (QU-Droop, } \\
\text { Voltage Control based Congestion } \\
\text { Management) }\end{array}$} & \multicolumn{2}{|c|}{$\begin{array}{l}\text { III. DER/P-Control (PU-Droop, Voltage } \\
\text { Control based Congestion Management) }\end{array}$} & $\begin{array}{l}\text { IV. DER/P-Control (Peak Shaving, } \\
\text { Current Control based Congestion } \\
\text { Management) }\end{array}$ \\
\hline 1 & \multicolumn{2}{|c|}{$\begin{array}{l}\text { Mainly grid-code-based, some aggregation } \\
\text { pilots for market-based participation }\end{array}$} & \multicolumn{2}{|c|}{$\begin{array}{l}\text { Primary local voltage control method } \\
\text { with fixed settings }\end{array}$} & Secondary & $\begin{array}{l}\text { voltage control method (after } \\
\text { with fixed settings }\end{array}$ & $\begin{array}{l}\text { Estimations based on load situation about } \\
\text { possible peak shaving needs and } \\
\text { restrictions related to I., coordination with } \\
\text { V. }\end{array}$ \\
\hline 3 & \multicolumn{2}{|c|}{$\begin{array}{l}\text { Increasingly real-time adaptive settings } \\
\text { (depending e.g. on the inertia-level), } \\
\text { coordinated settings with III. and IV. }\end{array}$} & \multicolumn{4}{|c|}{$\begin{array}{l}15 \mathrm{~min} / \text { real-time adaptive (also frequency deviation adaptive), coordinated settings with } \\
\text { III., VI. and VII. }\end{array}$} & $\begin{array}{l}\text { Increased amount of real-time accurate } \\
\text { measurement to maximise capacity } \\
\text { utilisation and coordination with I. }\end{array}$ \\
\hline \multicolumn{8}{|c|}{ The colors are the same meaning in Figure 3, same with Tables 4 and 5 . } \\
\hline & & \multicolumn{6}{|c|}{ Adaptive Control and Management Methods } \\
\hline & & \multicolumn{2}{|c|}{$\begin{array}{l}\text { I. DER/Pf-Control } \\
\text { (Frequency Control) }\end{array}$} & \multicolumn{2}{|c|}{$\begin{array}{l}\text { II. DER/Q-Control ( } Q U \text {-Droop, } \\
\text { Voltage Control based Congestion } \\
\text { Management) }\end{array}$} & $\begin{array}{l}\text { III. DER/P-Control (PU-Droop, } \\
\text { Voltage Control based Congestion } \\
\text { Management) }\end{array}$ & $\begin{array}{l}\text { IV. DER/P-Control (Peak Shaving, } \\
\text { Current Control based Congestion } \\
\text { Management) }\end{array}$ \\
\hline \multicolumn{2}{|c|}{$\begin{array}{l}\text { Local (DSO)/System-wide } \\
\text { (TSO) Service }\end{array}$} & \multicolumn{2}{|l|}{ TSO } & & DSO (at stages $1-3)$ & $\begin{array}{l}\text { ges 1-3) } \\
\text { ere frequency deviations) }\end{array}$ & DSO \\
\hline \multicolumn{2}{|c|}{ Location-based prioritization } & \multirow{2}{*}{\multicolumn{2}{|c|}{$\begin{array}{l}\text { Location and Frequency range-dependent priority, } \\
\text { i.e., DER closer to the TSO network, will be used } \\
\text { already at smaller frequency deviations } \\
\text { In case of expected network congestions (voltage or } \\
\text { thermal/current related) in DSO network } \\
\text { participation on TSO services are not allowed } \\
\text { (stage 1) OR it can be dependent on the severity of } \\
\text { the frequency deviation (stage 2-3) }\end{array}$}} & \multicolumn{3}{|c|}{$\begin{array}{l}\text { TSO (at stages } 2-3 \text { during severe frequency deviations) } \\
\text { DER as close as possible to the congestion should be prioritized, and further in LV } \\
\text { network-connected DER units' QU-droops should have larger dead-zones than } \\
\text { directly MV network or MV/LV substation connected larger DER units }\end{array}$} & $\begin{array}{l}\text { DER as close as possible to the } \\
\text { congestion should be prioritized }\end{array}$ \\
\hline \multicolumn{2}{|c|}{$\begin{array}{l}\text { DSO network state-based } \\
\text { prioritization }\end{array}$} & & & \multicolumn{3}{|c|}{$\begin{array}{l}\text { At stage 2-3, the DER unit setting could be adaptive and dependent on the severity of } \\
\text { the frequency deviation (TSO frequency support enabling during large deviations) }\end{array}$} & $\begin{array}{l}\text { At Stage } 1 \text {, priority on IV. before V. and at } \\
\text { Stage 2-3 frequency range-based priority }\end{array}$ \\
\hline & er Issues & 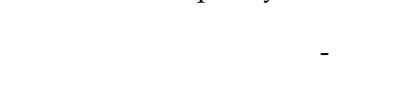 & & - & & $\begin{array}{l}\text { At Stage 1, conflicts with other functions } \\
\text { (I. \& IV.) possible without coordination } \\
\text { and prioritisation }\end{array}$ & רs \\
\hline
\end{tabular}


Table 5. Adaptive control and management methods V.-VII. evolution during different stages 1-3 and related issues. (see Figure 3, Tables 3 and 4).

\begin{tabular}{|c|c|c|c|}
\hline & \multicolumn{3}{|c|}{ Adaptive Control and Management Methods } \\
\hline Stage & $\begin{array}{c}\text { V. OLTC/CVR } \\
\text { (Peak Shaving, Current Control } \\
\text { based Centralised Congestion } \\
\text { Management by Voltage } \\
\text { Reduction) }\end{array}$ & $\begin{array}{c}\text { VI. Adaptive OLTC } \\
\text { (Voltage Control, DER \& EV Hosting Capacity) }\end{array}$ & $\begin{array}{c}\text { VII. DER/Q-Control (PQ Flow Management between } \\
\text { Voltage Levels or at DER, Household, Microgrid etc. } \\
\text { Connection Point) }\end{array}$ \\
\hline 1 & Current dependent fixed setting $\left.{ }^{*}\right)$ & Fixed or seasonally adaptive setting value & Yearly/seasonal $P Q$-target window \\
\hline 2 & -1 & $\begin{array}{l}\text { Monthly/weekly/daily adaptive OR } \\
\text { Real-time PQ flow-dependent (VII.) setting value, } \\
\text { coordinated settings with II. and III. }\end{array}$ & $\begin{array}{c}\text { Monthly/Weekly } P Q \text {-target window, coordinated settings } \\
\text { with II. and VI. }\end{array}$ \\
\hline${ }^{2}$ & - & $\begin{array}{l}\text { Depending on the frequency level/range the setting value is } \\
\text { based on real-time } P Q \text { flow (DSO service) OR frequency level } \\
\text { (TSO service) (VII.), coordinated settings with II. and III. }\end{array}$ & $\begin{array}{c}\text { Daily/Hourly } P Q \text {-target window, coordinated settings } \\
\text { with II. and VI. }\end{array}$ \\
\hline $\begin{array}{l}\text { Local (DSO)/system-wide } \\
\text { (TSO) service }\end{array}$ & $\mathrm{DSO}$ & $\mathrm{DSO} / \mathrm{TSO}$ & $\mathrm{DSO} / \mathrm{TSO}$ \\
\hline $\begin{array}{l}\text { location-based } \\
\text { prioritization }\end{array}$ & - & - & $\begin{array}{c}\text { DER as close as possible to the control point should be } \\
\text { prioritized }\end{array}$ \\
\hline $\begin{array}{l}\text { DSO network state-based } \\
\text { prioritization }\end{array}$ & & $\begin{array}{l}\text { At stage } 1 \text { for DSO needs (maximizing hosting capacity), } \\
\text { At stage 2-3, frequency deviation-dependent operation, i.e., } \\
\text { during smaller frequency deviations use for DSO needs } \\
\text { (maximizing hosting capacity) and during larger frequency } \\
\text { deviations use for TSO needs (centralized demand response) }\end{array}$ & $\begin{array}{c}\text { At stage 2-3, frequency deviation-dependent operation, i.e., } \\
\text { normal operation during smaller frequency deviations for } \\
\text { DSO needs (maximizing hosting capacity) and during } \\
\text { larger frequency deviations use is disabled to avoid } \\
\text { unwanted effects between other frequency supporting } \\
\text { functions }\end{array}$ \\
\hline
\end{tabular}




\subsection{Adaptive DER Unit QU-Droops: Stage 2-3}

In order to achieve better voltage support and maximize PV and EV hosting capacity in distribution networks as well as improve the availability of distribution network-connected DER for provision of TSO flexibility services, the DER unit QU-droop settings could be real-time adaptive in the future at evolution stage 2 and 3 (Table 1) instead of time-based adaptation as presented in Table 3 and [81]. If the real-time OLTC setting value could be communicated to the DER unit, then it could be used as an input to adapt the DER unit $Q U$-droop settings, as shown in Figure 4. Regarding the other QU-droop settings (Figure 4), the constants could be chosen so that the location-based prioritization principles defined in Table 4 are also fulfilled. In case of communication failure, the seasonal/monthly, etc., time-based DER unit QU-droop settings adaptation could be used as a backup method.

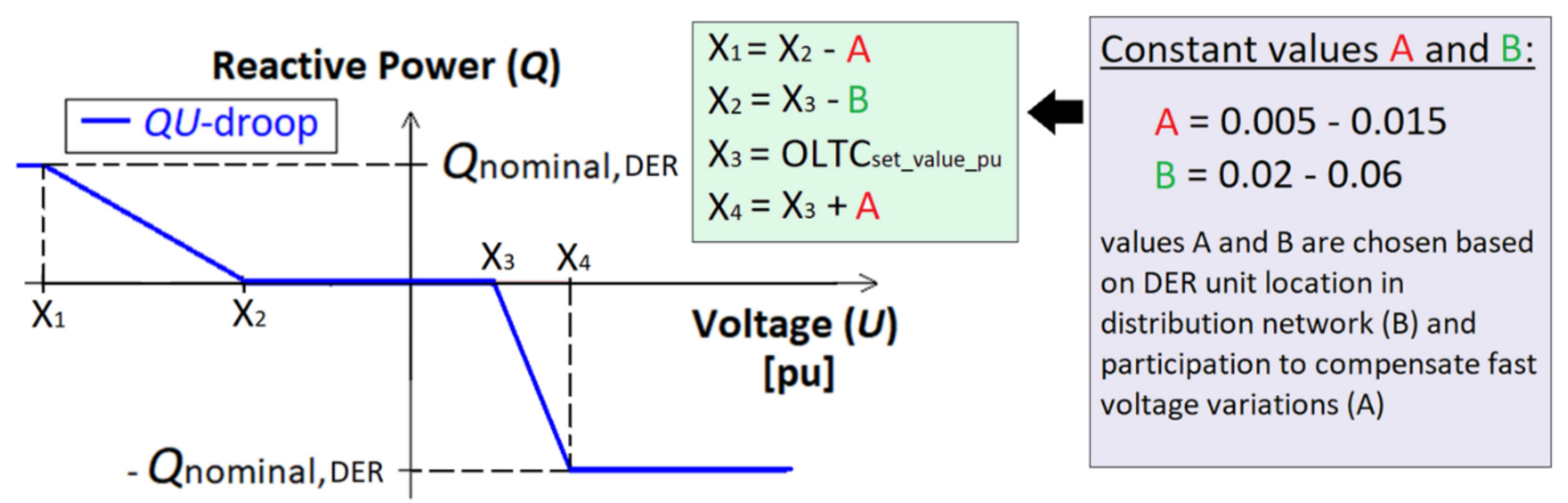

a)

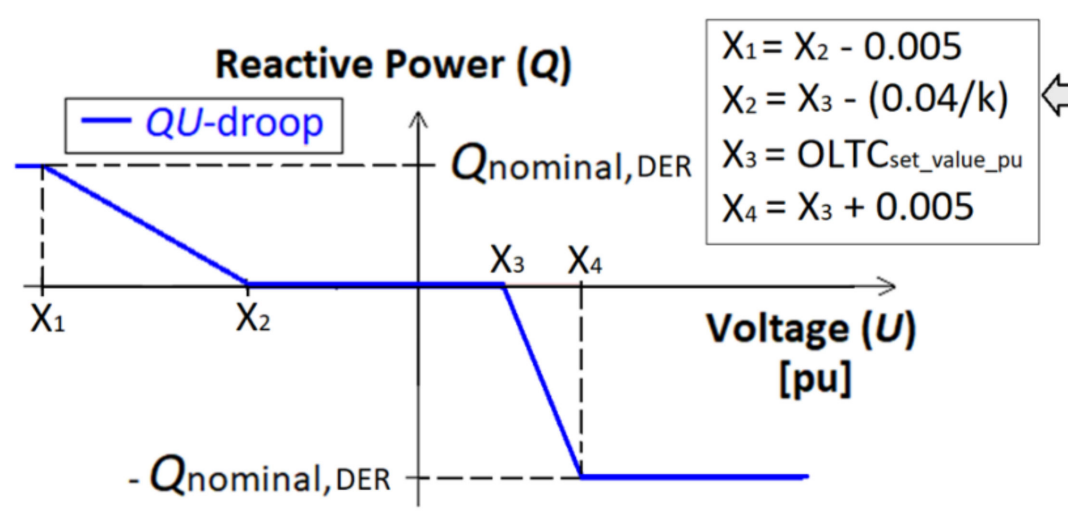

b)
Constant k value examples:

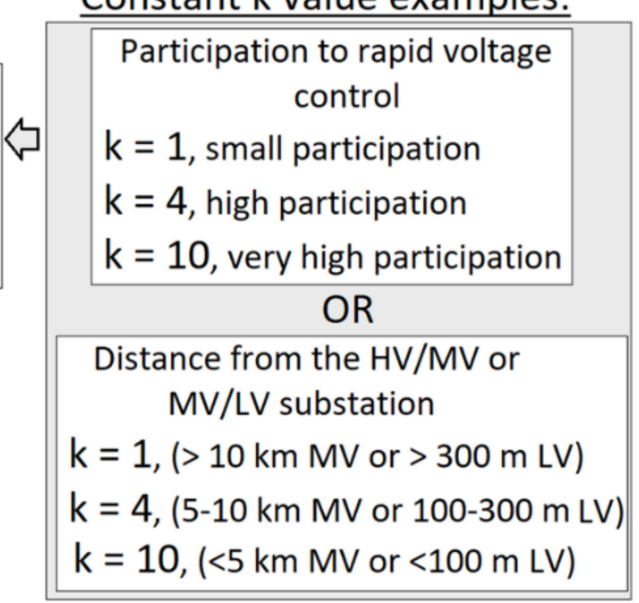

Figure 4. Real-time adaptive DER unit QU-droop-based on OLTC set value, OLTC setting value, location, and participation to rapid voltage control with (a) constants A and B [81] or (b) constant k (see Tables 3 and 4).

In addition, with DER units also participating in the control and management of $P Q$ flow between voltage levels or at the DER, household, or microgrid connection point (Table 5) by its reactive power control, the real-time adaptive $Q U$-droop could be further modified from Figure 4, as shown in Figure 5. 


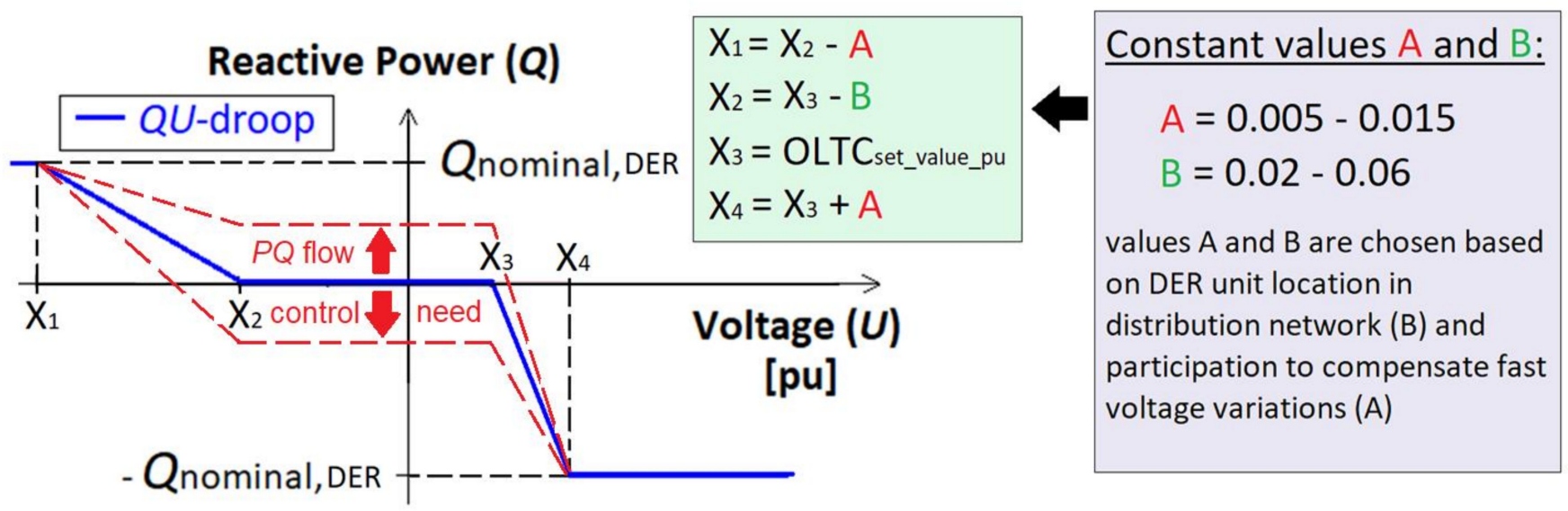

Figure 5. Real-time adaptive DER unit QU-droop based on OLTC set value, OLTC setting value, location, and participation on rapid voltage control, as well as participation on $P Q$ flow management (see Figure 4 and Tables 3 and 4).

As a further development from Figures 4 and 5, the QU-droop settings could in stage 3 be further enhanced with real-time measurements-based learning, i.e., based on previous local $Q$ and $U$ as well as connection point $P Q$ flow measurements and use of $\mathrm{AI}$ and ML techniques. Regarding the measurements-based learning, it could be only enabled when frequency stays between, e.g., $49.95-50.05$, in order to avoid confusion due to potential nearby DER units' $P f$-control effects on local voltages.

\subsection{Frequency Adaptive DER Unit PU-Droops: Stage 2-3}

As also presented in Table 3 and [81], the DER unit PU-droop settings could be frequency adaptive (Figure 6) at evolution stages 2-3 (Table 1). During larger frequency deviations, frequency adaptive $P U$-droops could enable larger PV and BESS power system frequency support as well as maximize smaller LV network-connected demand (loads) participation to frequency control [81]. On the other hand, the implementation could also be smoother without exact frequency and voltage limits for the activation of the frequency adaptive functionality, as shown in Figure $6 \mathrm{~b}$. A real-time frequency adaptive $P U$-droop for PV and BESS units (Figure 6b) was proposed in [81] when frequency deviation is between $\pm 1.0 \mathrm{~Hz}$ from the nominal frequency $f_{\mathrm{n}}$. If frequency deviation is larger, then similar settings will be used as if the deviation would be $1.0 \mathrm{~Hz}$ from $f_{\mathrm{n}}$. In Figure $6 \mathrm{~b}$, equations for $\mathrm{X}_{1}, \mathrm{X}_{2}, \mathrm{X}_{3}$, and $\mathrm{X}_{4}$

$$
\begin{gathered}
f=\text { measured frequency }(\mathrm{Hz}) \\
f_{\mathrm{n}}=\operatorname{nominal} \text { frequency }(\mathrm{Hz}) \\
U_{\text {min_ini }}=\text { chosen initial minimum voltage set-point value when } f=f_{\mathrm{n}}(\mathrm{pu}) \\
U_{\text {max_ini }}=\text { chosen initial maximum voltage set-point value when } f=f_{\mathrm{n}}(\mathrm{pu}) \\
P_{\mathrm{n}}=\text { nominal active power }(\mathrm{MW})
\end{gathered}
$$

\subsection{Real-Time $P Q$ Flow-Dependent OLTC Setting Value: Stage 2}

In stage 2 (Tables 1 and 4, Figure 3), instead of seasonal OLTC settings, the OLTC setting value could be based on locally-measured real-time active and reactive power flow levels (5 min average $P_{\mathrm{HV}}$ and $Q_{\mathrm{HV}}$ values) between $\mathrm{HV}$ and MV networks at the HV /MV substation, as shown in Figure 7. The Figure 7 example is based on Sundom Smart Grid $P Q$ flow -limits [80]. This proposed new $P Q$ flow-dependent OLTC setting value calculation could further increase DER and PV/EV hosting capacity (from the voltage limits point of view) in distribution networks, and simultaneously, the availability of demand response for provision of system-wide frequency support could be increased. The proposed $P Q$ flow-dependent OLTC setting value (Figure 7) is based on local measurements only and 
does not require knowledge about minimum and maximum voltages in the corresponding distribution network (LV and MV). Therefore, this approach could be further improved in the future in stage 2 with the real-time measurements-based data in order to achieve even more fine-tuned and optimized OLTC set values as well as compatible settings for the real-time adaptive $Q U$-droops of the DER units (Section 3.1).

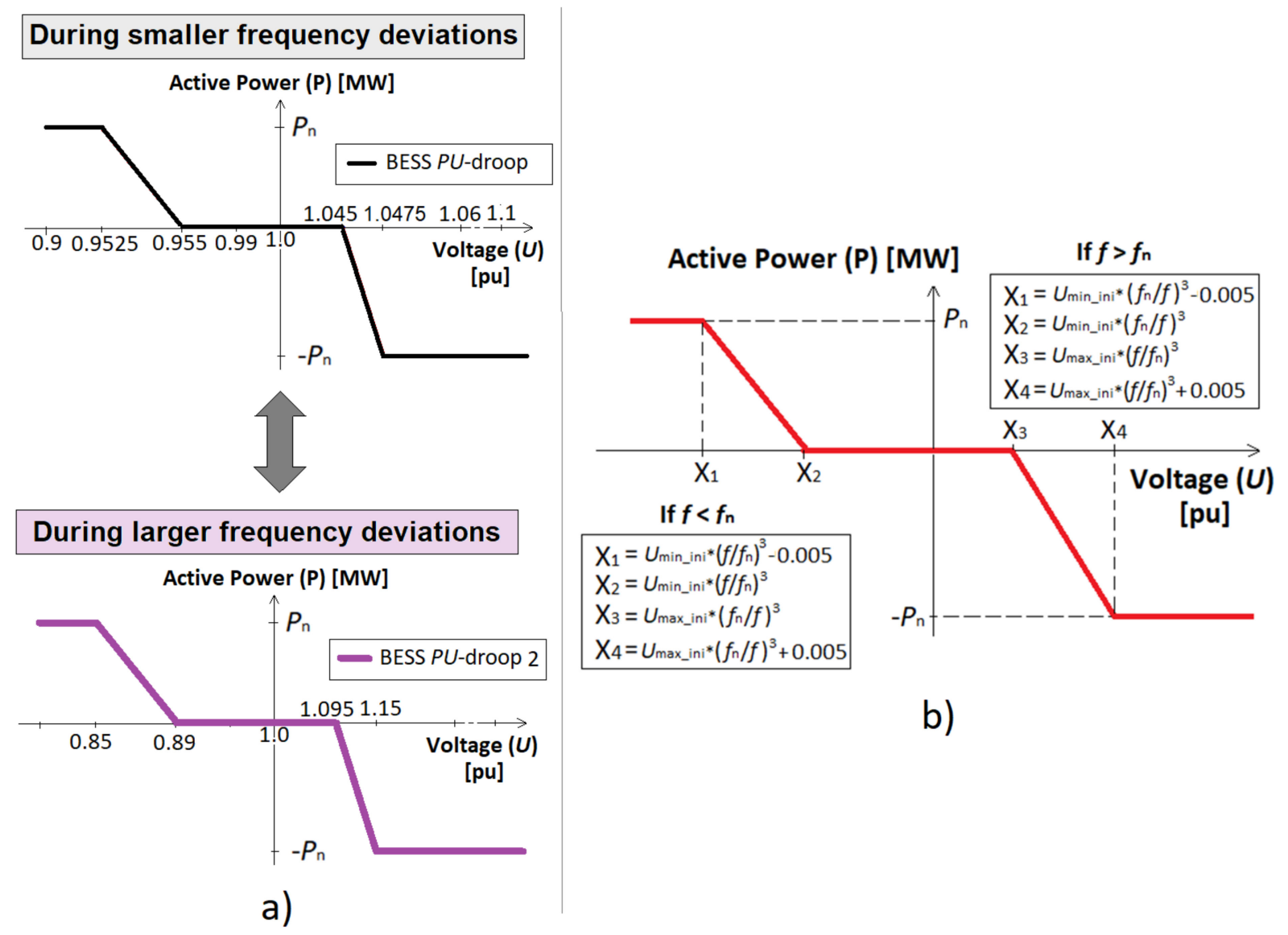

Figure 6. (a) Frequency adaptive DER unit PU-droop for a BESS during smaller and larger under and over-frequency situations and (b) Real-time smooth-frequency adaptive $P U$-droop without specific frequency and voltage limits for activation, e.g., for BESS unit [79] (see Tables 3 and 4).

If adaptive OLTC control at stages $2-3$ (Table 5) will be increasingly frequency deviation-dependent during larger frequency deviations, then it needs to be also taken into account how these different adaptive OLTC functionalities affect each other and the number of available flexibility services.

\subsection{Adaptive PQ Flow Control Window: Stages 1-3}

In order to improve the coordinated provision of flexibility services by flexible active $P$ and reactive power $Q$ resources located at different voltage levels, different type of $P Q$ flow control windows at different levels/connection points (HV/MV, MV/LV, LV customer connection point) could be applied in the future at different evolution stages 1-3. This means, for example, that outer limits of Figure $7 P Q$ flow control window or reactive power window (RPW) or operating envelope [82] at the HV/MV substation could be more dynamic/adaptive and take the changing needs of DSOs and TSOs into account in realtime. Therefore, more accurate reactive power availability and needs forecasting for control purposes, e.g., $P Q$ flow control windows between different voltage levels/connection points, will increasingly be needed as more intensive DSO/TSO cooperation is realized during the power system evolution. It should also be taken into account that the $P Q$ flow 
limits should not unnecessarily restrict the flexibility services provision to upper voltage levels (e.g., from MV network to HV network). On the other hand, dynamic $P Q$ flow control window HV and MV networks could be used to better support the voltage and angle stability issues (or prevent potential issues and improve power system resiliency) depending on the HV network power flow situation. In addition, the $P Q$ flow control window (Figure 7) outer limits could be further fine-tuned and adapted based on the changed OLTC value (unlike in Figure 7). Realization of these would also require the development of related market and tariff structures.

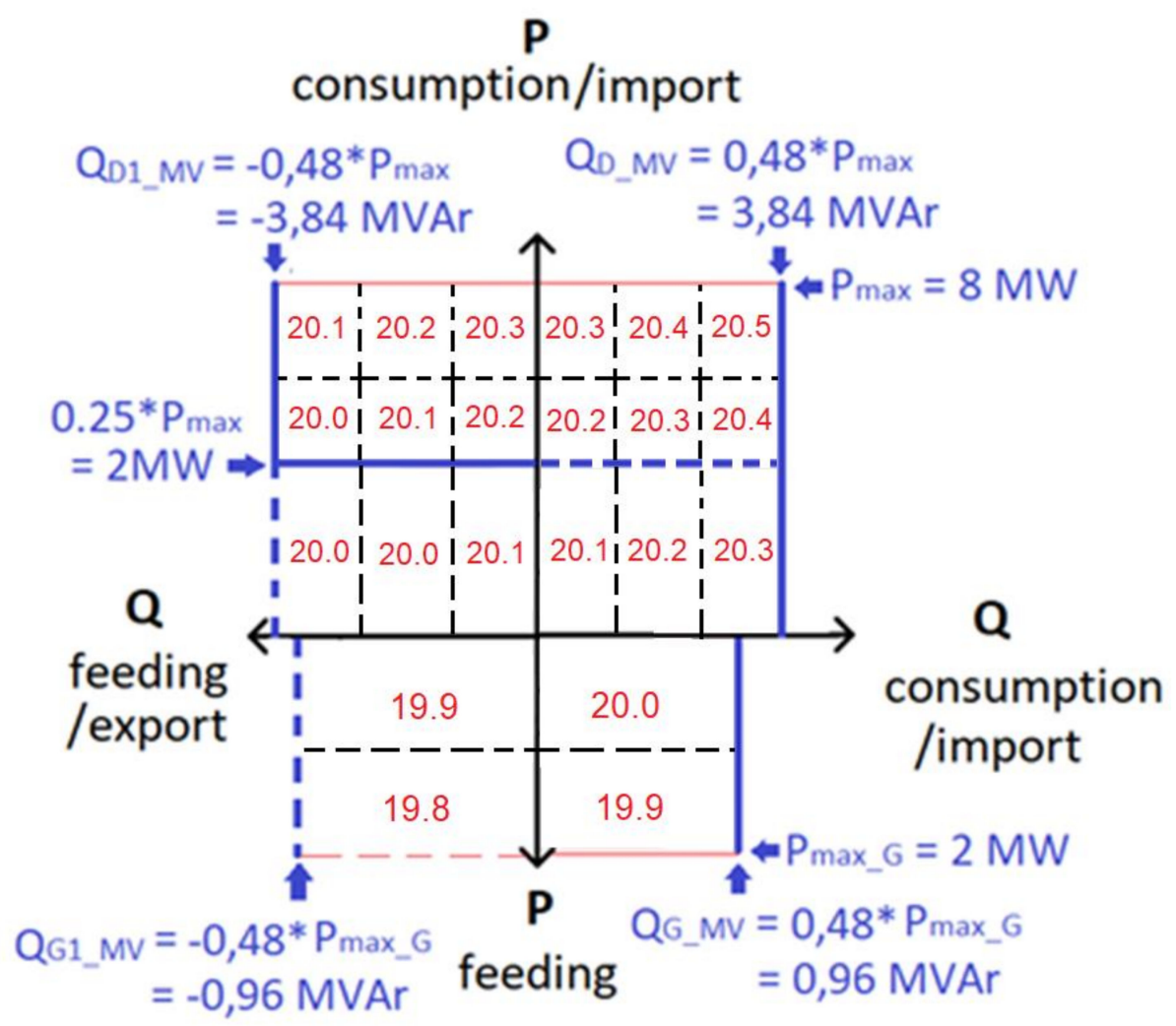

Figure 7. Real-time HV/MV substation $P Q$ flow-dependent OLTC setting value $(\mathrm{kV})$ with Sundom Smart Grid $P Q$ flow limits (see Table 5 and Figure 3).

As stated in Table 5, the location of DER units as close as possible to the control point should be prioritized in $P Q$ flow control participation. At stage 2-3, frequency deviationdependent operation should be preferred (Table 5), which means that the $P Q$ flow control functionality would be disabled during larger frequency fluctuations to avoid unwanted effects between other frequency supporting functions.

In stage 1, adaptive (i) $P Q$ flow control or RPW limits could be applied between HV (TSO) and MV (DSO) networks so that the seasonal flexibility needs of TSO networks and DSO networks are considered and (ii) customer connection point (household, SME, school, etc., (Figure 3) power factor $\cos (\phi)$ settings e.g., $\cos (\phi)=1$ (winter) and $\cos (\phi)=0.95_{\text {ind }}$ (summer) could be applied at customer connection points. In addition, extended seasonal $\cos (\phi)$ settings at customer connection points could be used, which also take into account local voltage $(U)$ and /or current $(I)$ /active power $P$ flows at the connection point. In the next stages, $2-3$, more specific, adaptive daily and hourly $P Q$ flow control windows for different connection points ( $\mathrm{HV} / \mathrm{MV}, \mathrm{MV} / \mathrm{LV}$, customer connection point, power-electronic- based normally open points, i.e., soft-open points/SOPs including also potential smart power electronic transformers at $\mathrm{HV} / \mathrm{MV}$ or MV/LV substations) could be added (Figure 3). These could enable more optimized real-time operation of the TSO and DSO networks by using flexibility services from different types and sizes of resources 
through flexibility markets and consideration of potential DSO network constraints (e.g., voltage and thermal/current limits).

\section{Market Schemes for Adaptive Control and Management Methods Collaborative TSO-DSO Use}

During the evolution, flexibilities efficient use requires new enabling business models, market structures, and marketplaces [83] as well as regulation development [84]. In addition, quite recently, different types of flexibility aggregation platforms and marketplaces have been developed, e.g., Equigy [85] and NODES [86,87], as well as proposed in different research projects such as FLEXIMAR [88,89]. For example, in [90], the aggregation platform for flexibility (APF) is presented, which can be used to sell flexibility on multiple markets. In [91,92], another platform (Distributed Energy Resource Management Systems, DERMS) has been presented, which is a centralized control system that enables DERs connected to the distribution network to provide services to the TSO in the U.K., in a coordinated and controlled manner by also taking into account DSO requirements and needs. In [92], it is stated that in the future, DERMS and ANM systems together will provide the possibility to manage the potential conflicts of services between TSOs and DSOs for both simple and complex networks.

\subsection{Local Trading and Markets in Distribution Networks}

In the future, the more detailed definition and study of transition paths between the evolution stages, e.g., regarding simultaneous development of local energy communities and market structures as well as related regulation, will also need to be focused on. It might also be worth considering that bilateral contracts between the flexibility providers (household customer, microgrid, local energy community, etc.) in some cases could be the first ANM business model at the DSO level (for DSO needs) before applying full-scale DSO level local flexibility markets.

In typically proposed peer-to-peer (P2P) markets, the cost has been the only considered parameter in order to minimize the customer energy costs. However, in more developed and transparent future P2P markets, other values and customer choice preferences could also be considered. These could be related, for example, to energy resource type, location, supplier, etc. This kind of customer preferences management needs also applies to future local/system-wide flexibility markets and customers participating in different markets simultaneously. However, privacy and security aspects should also be carefully considered when increasing transparency and customer choices. Potentially, different kinds of preferences could be integrated and managed blockchain-based P2P energy and/or future flexibility market structures.

Different potential future market architectures have also been presented, for example, in [55,93-100]. Paper [93] proposes a blockchain-based platform for local energy trading within a regional market as well as grid services for the observance of grid restrictions; the next aim is to demonstrate the platform in field tests [93]. In [101], a blockchain-based authorization system for resource monitoring and trading in smart communities is also presented. Blockchain and multi-agent or P2P-based controls for energy communities and local marketplaces have also been presented in [94,95,102-104]. In the future market designs, the coordination with other energy vectors (heat, hydrogen, natural gas, industrial, and so on), BESSs/other energy storages as well as with transportation (such as EVs), must also increasingly be considered simultaneously in order to achieve maximum whole system and societal benefits [83]. However, the applicability of P2P control, e.g., for frequency control purposes, may be challenging and therefore, e.g., broadcast-based [105] approaches have been proposed.

In [106], the need for a radical change in the future electricity market design for a mainly renewables-based power system is highlighted. It illustrates how current, mainly energy market-focused, the market structure needs to evolve between 2020-2030 toward a more diverse market structure with a greater focus on ancillary/flexibility service and capacity markets. As stated in [106], the market design focus in the future will also shift 
from the operation timescale and the short-run marginal cost of the system toward the investment timescale and the related capital investments to support the future carbonneutral energy system. In addition, flexibility service types should be considered as a key factor in flexibility market design. In other words, it is necessary to consider the types of flexibility services and accordingly use the resources which are able to provide each specific service. For example, some flexibility services for the TSO need to be symmetric, i.e., suitable resources must be able to provide bi-directional flexibility.

In addition to new market-based schemes for flexibilities use, new types of distribution system (DSO) tariff structures could also be introduced in the future to support the use of renewables and flexibilities, coupling between different energy vectors, and to take into account the network state in real-time. This could be realized, for example, by (i) dynamic real-time tariff using an increased number of MV and LV sensor measurements, cloud-/edge server solutions, big data analytics, etc.; (ii) distribution tariff structures that support the whole system cost minimization; and (iii) the possibility to take into account location (voltage level) as part of the distribution tariff.

In [105], the authors made an assessment of the different mechanisms (time of use, ToU tariffs, dynamic tariffs, finer geographical granularity, bilateral agreements, and local flexibility markets) for unlocking the flexibility potential of demand. The used criterions included (i) effectiveness on congestion management, (ii) ease of implementation, (iii) market compatibility considering TSO, DSO, and feeder viewpoints, as well as (iv) impact on system balancing in general. Based on the assessment, local flexibility markets effectiveness, for example, on (i) and(iii) is high for TSO, DSO, and feeder, (ii) is medium, and(iv) is neutral. The Danish Energy Authorities have also started the market design for local flexibility markets focusing on ensuring power system security via market-based solutions, enhancing the role of flexibility from prosumers and other new actors, and the DSO's role development in the market [107].

\subsection{TSO-DSO Collaborative Market Scheme}

As stated previously, the new adaptive control/management and market schemes, such as flexibility markets, have to be compatible with each other and act as enablers of the evolution as well as increased TSO-DSO collaboration. New market structure and flexibility marketplace(s)/platform(s) can enable maximization of flexibilities collaborative value in the future. Table 6 presents the potential evolution of market schemes during stages 1-3, with a special focus on frequency control markets as well as compatibility with the adaptive control and management methods/principles defined in Tables 2-5. When considering, for example, stage 2 in Table 6 , it is seen that the general market structure will develop so that it enables increased use and participation of DSO network-connected DER for the provision of active power control-related services through local/regional flexibility markets. Simultaneously reactive power markets will also be integrated into the flexibility markets. In order to also increase customers/prosumers' participation motivation/incentives at stages 2 and 3 for flexibility services provision, simultaneous use of dynamic distribution tariffs (Table 6), together with enlarged flexibility markets (including also reactive power markets), could be increasingly applied with compatible technical solutions and adaptive control and management methods described in Section 3 (Tables 2-5). At stage 3, flexibility markets could be even further enlarged with MV and LV network local power quality improving markets related to current/voltage phase asymmetry and harmonics compensation (need for these increases due to increased integration of EVs and PVs). 
Table 6. Collaborative (TSO-DSO) and adaptive control and management methods compatible (Tables 2-5) market schemes evolution during different stages 1-3 with special focus on frequency control markets (see Figures 3 and 8).

\begin{tabular}{|c|c|c|c|c|c|c|c|}
\hline Stage & $\begin{array}{c}\text { General Market Structure } \\
\text { (for Increased } \\
\text { Participation of DER } \\
\text { Active Power Resources) }\end{array}$ & $\begin{array}{c}\text { DER Participation on } \\
\text { TSO Frequency Control } \\
\text { Markets }\end{array}$ & \multicolumn{4}{|c|}{ Frequency Ranges } & $\begin{array}{l}\text { Other New Local (DSO } \\
\text { Level) Mar- } \\
\text { kets/Tariffs/Agreements }\end{array}$ \\
\hline 1 & $\begin{array}{l}\text { Pilots regarding local } \\
\text { flexibility markets } \\
\text { aggregated participation } \\
\text { of distribution } \\
\text { network-connected DER } \\
\text { to existing TSO level } \\
\text { markets }\end{array}$ & $\begin{array}{c}\text { Principles and } \\
\text { prioritization (e.g., } \\
\text { location and DSO } \\
\text { network-based, } \\
\text { Tables 2-4) of DSO } \\
\text { network-connected } \\
\text { flexible energy resources } \\
\text { participation to TSO } \\
\text { frequency control services } \\
\text { provision through FFR, } \\
\text { FCR-N, and FCR-D } * * * \\
\text { marketplaces }\end{array}$ & $\begin{array}{l}\text { (upregul } \\
49.7 \mathrm{~Hz} \\
1.3 \mathrm{~s}\end{array}$ & $\begin{array}{r}\mathrm{F} \\
\text { ion during und } \\
49 . \\
1 \\
\mathrm{FC} \\
\text { (symmetric, } \\
49.9-50.1 \\
\mathrm{FC} \\
\text { (symmetric, } \\
49.5-49.9 \text { and 5 }\end{array}$ & $\begin{array}{l}\text {-frequencies, m } \\
\mathrm{Hz} \\
\mathrm{s} \\
-\mathrm{N} \\
\text { in. } 0.1 \mathrm{MW}) \\
\mathrm{Iz}, 3 \mathrm{~min} \\
-\mathrm{D} \\
\text { in. } 1 \mathrm{MW}) \\
1-50.5 \mathrm{~Hz}, 30 \mathrm{~s}\end{array}$ & $\begin{array}{l}1 \mathrm{MW}) \\
49.5 \mathrm{~Hz} \\
0.7 \mathrm{~s}\end{array}$ & $\begin{array}{l}\text { MV network reactive power } \\
\text { control market and dynamic } \\
\text { tariffs/distribution use of } \\
\text { system (DUoS charges) } \\
\text { pilots and bilateral } \\
\text { agreements }\end{array}$ \\
\hline 2 & $\begin{array}{l}\text { Local (e.g., microgrids) } \\
\text { flexibility and regional * } \\
\text { flexibility market } \\
\text { implementations }\end{array}$ & $\begin{array}{l}\text { Frequency levels } 1-4 \text { and } \\
\text { prioritized use of DSO } \\
\text { network-connected DER } \\
\text { (Tables 2-4) }\end{array}$ & $\begin{aligned} & 1^{* *} \\
\leq & \pm 0.1 \mathrm{~Hz}\end{aligned}$ & $\begin{array}{c}2^{* *} \\
\pm 0.1-0.2 \mathrm{~Hz}\end{array}$ & $\begin{array}{c}3^{* *} \\
\pm 0.2-0.5 \mathrm{~Hz}\end{array}$ & $\begin{array}{c}4 \\
\geq \pm 0.5 \mathrm{~Hz}\end{array}$ & $\begin{array}{c}\text { Dynamic tariffs /DUoS } \\
\text { charges, MV network } \\
\text { reactive power control } \\
\text { markets }\end{array}$ \\
\hline 3 & $\begin{array}{c}\text { Two-level marketplaces => } \\
\text { regional * marketplaces } \\
\text { consisting of multiple } \\
\text { local flexibility } \\
\text { marketplaces }\end{array}$ & $\begin{array}{l}\text { More frequency levels th } \\
\text { depending on th }\end{array}$ & $\begin{array}{l}\text { at stage } 2 \text {, i.e } \\
\text { al-time and } f\end{array}$ & $\begin{array}{l}\text { smaller frequen } \\
\text { ecasted power }\end{array}$ & $\begin{array}{l}\text { y ranges }(+/- \\
\text { stem inertia les }\end{array}$ & $\begin{array}{l}5-0.1 \mathrm{~Hz}) \\
* *\end{array}$ & $\begin{array}{l}\text { MV and LV network local } \\
\text { power quality improving } \\
\text { service markets } \\
\text { (current/voltage phase } \\
\text { asymmetry and harmonics } \\
\text { compensation) }\end{array}$ \\
\hline
\end{tabular}

${ }^{*}$ Here, regional means one TSO network area (region) in which one or more DSOs can be present. ${ }^{* *}$ All frequency level/range markets are symmetric (support for under- and over-frequencies), minimum bid size could be $0.05-0.1 \mathrm{MW}$, and time to full activation is dependent on the level, type, and size of the resource (e.g., at stage 2: Level 1/0.5-5 s, Level 2/0.5-10 s, Level 3/0.5-30 s), see Figure 8. *** Currently used TSO frequency control markets in Europe/Nordic countries (FFR, FCR-N, FCR-D, aFRR, and mFRR, where FFR is fast frequency reserve, FCR-N is frequency containment reserve-normal, FCR-D is frequency containment reserve-disturbance, aFRR is automatic frequency restoration reserve, and $\mathrm{mFRR}$ is manual frequency restoration reserve).

As an example, Figure 8 also shows DSO network-connected DER possible participation in the provision of TSO frequency control services at evolution stage 2 (Tables 1-6) through different frequency control markets (Table 6), also considering the location of DER as well as possible DSO network congestions (Tables 2-5). In addition, as stated in Table 5, at stages $2-3$, frequency deviation-dependent adaptive OLTC operation during larger frequency deviations (e.g., at level 3 in Table 6 and Figure 8) could be used for frequency support through markets as centralized demand response. Respectively, during smaller frequency deviations at evolution stage 2 (e.g., at level 1-2 in Table 6 and Figure 8), adaptive OLTC operation would be used for maximizing distribution network hosting capacity (e.g., EVs and PVs) and availability of DSO network-connected DER for TSO services provision by minimizing voltage limits-related congestions in MV and LV networks as far as possible by also coordinating DER unit droop settings with OLTC set value (Tables 2-5, Figures 3-8).

In the future, during evolution stages 2-3, more accurate real-time state estimation and state-forecasting will be essential. Regarding this, for example, time-synchronized real-time measurements from the distribution network (e.g., at certain MV/LV substations) could be used for improved state knowledge, which is the input needed, for example, for congestion management (Figure 8). Accurate state knowledge can simultaneously ensure that the current thermal and voltage limits of the MV and LV lines are not exceeded, but also that full MV and LV line/feeder capacity, as well as DER flexibility service potential and market participation (Table 6), can be used. Some of the potential DSO and TSO flexibility services and related functionalities (Figure 3 and Tables 2-5) may have mutual effects and momentary conflicts of interest. Partially, this challenge could be avoided by the use of different flexibility services and functionalities only at predefined frequency deviation levels/ranges as well as by also considering the type and location of the DER unit providing the services (Tables 2-6 and Figure 8). Potential mutual effects between all the different functionalities should be carefully considered. However, some of the functionalities may also complement each other, i.e., be in the same direction. 


\section{MV and LV network congestion lights}

Determine the possibility to utilize DSO network-connected DER for TSO services

( $P f$-control in this case)

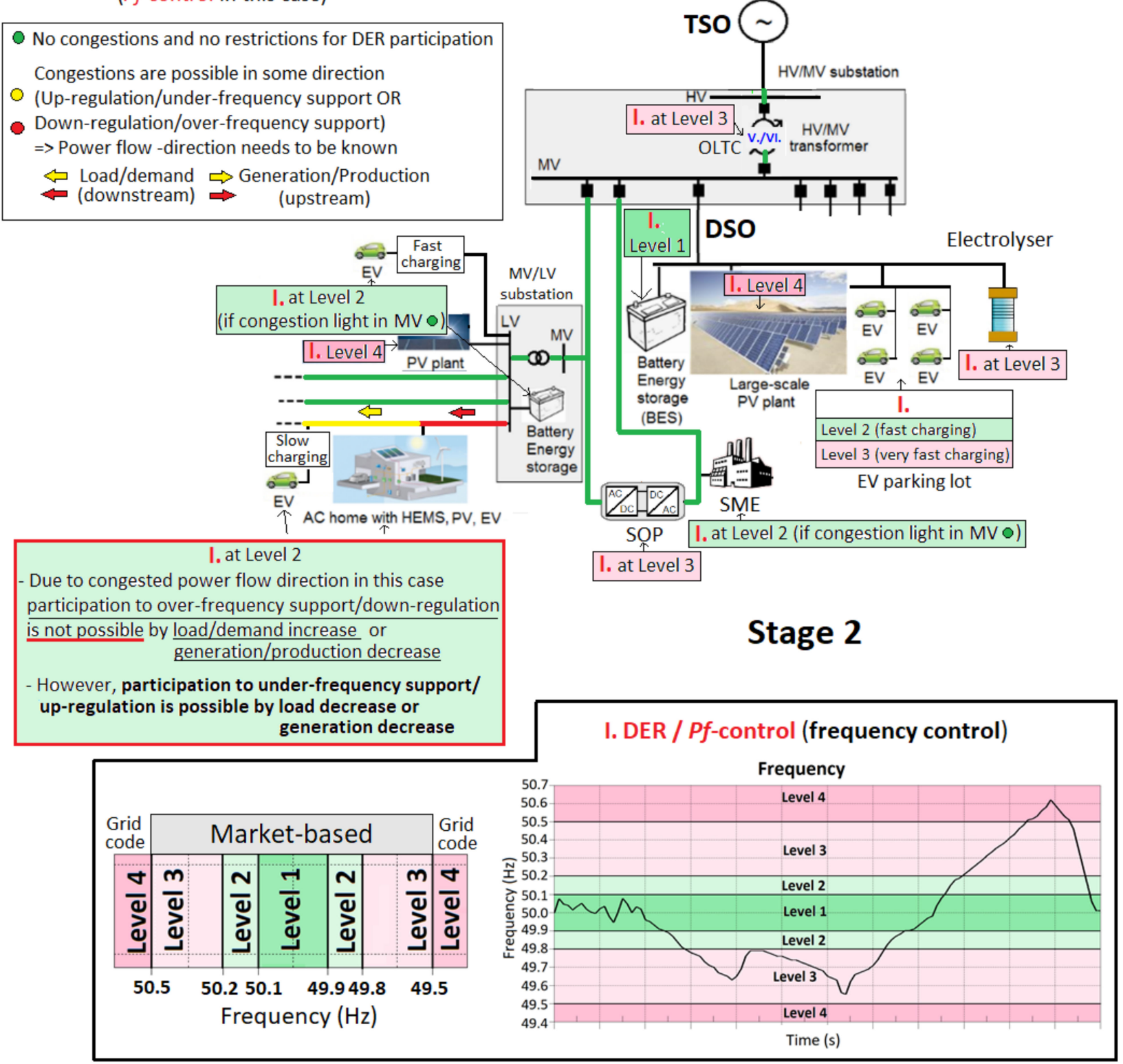

Figure 8. DSO network-connected DER participation on the provision of TSO frequency control services at evolution stage 2 through different markets also considering the location and type of DER as well as possible DSO network congestions (see Tables 1-5 and Figure 3).

\subsection{Sector Coupling and Energy Systems Integration Through Flexibility Market Participation}

Flexibility services provision by the integration of different sectors, for example, by use of EV batteries, electric heating/electric heat storages as well as electrolysis to produce greed hydrogen [108,109], is increasingly important in future power systems. However, the coordinated operation of an integrated energy system and a distribution network is also increasingly crucial [110]. Slow-charging of EVs at home could be used to participate in the frequency control market, e.g., at evolution stage 2 by disconnecting or stopping charging at level 2 under-frequencies (Figure 8). On the other hand, fast EV charging stations (Figure 8) could participate in frequency control at frequency level 3 deviations (priority on fast 
charging). This could be realized by adaptive charging with one-directional chargers during frequency level 3 under-frequencies or adaptive charging/discharging with bi-directional chargers at level 3 under- and over-frequencies. Regarding different types and sizes of BESSs' use for frequency control support, it would be beneficial from a DSO, and TSO needs a point of view if centralized BESS units at HV/MV substations could be used for $P f$ control at frequency deviation level 1 and distributed BESSs at MV/LV substations and LV networks at level 2 (Figure 8). Respectively, distributed BESSs could be used primarily for DSO needs (through $P$ - $/ P U$ - and $Q U$-control) during frequency level 1 deviation (Figure 8), such as for mitigation of voltage level fluctuations and voltage or thermal congestions, e.g., due to large-scale integration of PVs and EVs. In practice, the active $P f$-control potential of EVs and BESSs during charging is also dependent on different factors (e.g., battery chemistries, $\mathrm{SOC}$, and charging principle $(\mathrm{CC} / \mathrm{CV}$, i.e., constant current/constant voltage)), which should be considered when they are increasingly used for flexibility services provision during evolution stages $2-3$. In the future, EVs or EV one-/bi-directional charging stations could also have a similar $Q U$-droop to other DER units.

\section{Conclusions}

In the future, active use of distribution network-connected flexible energy resources (also LV network-connected, small-scale) for DSO and TSO flexibility services provision through new marketplaces will be needed. This paper presented three-stage evolution paths toward fully flexible, resilient, and digitalized electricity distribution networks. A special focus of this paper was the evolution of new adaptive control and management methods as well as compatible collaborative market schemes that could enable the improved provision of flexibility services by distribution network-connected resources.

This paper described potential adaptive control and management methods and principles evolution (Section 3) that could enable increased TSO-DSO collaboration during stages 1-3. In addition, compatible market schemes evolution during stages 1-3 was presented (Section 4) with close attention to frequency control markets. Regarding possible new adaptive control and management methods, especially the use of real-time adaptive DER unit $Q U$-droops, frequency adaptive DER unit $P U$-droops, real-time $P Q$ flow-dependent OLTC setting value, and adaptive $P Q$ flow control window were proposed and discussed in greater detail. As a final conclusion, it can be stated that the presented evolution of collaborative management methods and related market schemes could enable the flexible energy resources collaborative value and resiliency maximization from the whole system viewpoint by also considering the proposed location $n$, as well as real-time DSO network state-based prioritization principles, in the use of DSO network-connected flexible resources and active network management schemes.

Author Contributions: H.L.: Conceptualization, Methodology, Investigation. H.L., H.K., C.P., and M.S.-k.: Writing-Original draft preparation. H.K., C.P., M.S.-k., and N.H.: Writing-Reviewing and Editing. All authors have read and agreed to the published version of the manuscript.

Funding: This work was undertaken as part of the FLEXIMAR project (novel marketplace for energy flexibility) with financial support provided by Business Finland (Grant No. 6988/31/2018) as well as Finnish companies.

Institutional Review Board Statement: Not applicable.

Informed Consent Statement: Not applicable.

Conflicts of Interest: The authors declare no conflict of interest.

\section{References}

1. Bacher, R.; Peirano, E.; de Nigris, M. ETIP SNET—VISION 2050—Integrating Smart Networks for the Energy Transition: Serving Society and Protecting the Environment. Available online: https://www.etip-snet.eu/wp-content/uploads/2018/06/VISION2 050-DIGITALupdated.pdf (accessed on 2 February 2021). 
2. ETIP-SNET. Sector Coupling: Concepts, State-Of-The-Art and Perspectives, White Paper. January $2020 . \quad$ Available online: https:/ /www.etip-snet.eu/wp-content/uploads/2020/02/ETIP-SNEP-Sector-Coupling-Concepts-state-of-the-art-andperspectives-WG1.pdf (accessed on 3 February 2021).

3. ETIP-SNET. Holistic Architectures for Future Power Systems. 2019. Available online: https://www.etip-snet.eu/wp-content/ uploads/2019/03/ETIP-SNET_HolisticArchitecture_2019_04_01_Final.pdf (accessed on 2 February 2021).

4. De Heer, H.; van den Reek, W. USEF White Paper: Flexibility Platforms. 2018. Available online: https://www.usef.energy/app/ uploads/2018/11/USEF-White-Paper-Flexibility-Platforms-version-1.0_Nov2018.pdf (accessed on 22 February 2021).

5. Yi, Y.; Dong, W.; Li, A.; Sun, J.; Lian, X. Autonomous Operation of Power Distribution Area based on Edge Computing Framawork. In Proceedings of the CIRED 2020 Workshop, Berlin, Germany, 22-23 September 2020.

6. Strasser, T.; Andrén, F.; Kathan, J.; Cecati, C.; Buccella, C.; Siano, P.; Leitão, P.; Zhabelova, G.; Vyatkin, V.; Vrba, P.; et al. A Review of Architectures and Concepts for Intelligence in Future Electric Energy Systems. IEEE Trans. Ind. Electron. 2015, 62, 2424-2438. [CrossRef]

7. Li, K.F.; Tomsovic, H.; Cui, A. Large-Scale Testbed as a Virtual Power Grid: For Closed-Loop Controls in Research and Testing. IEEE Power Energy Mag. 2020, 18, 60-68. [CrossRef]

8. Brazier, R.; Cunha, L.; Hermans, P.; de Jong, G.; Knop, T.; Lallemand, M.; Merkel, M.; Risnes, A.S.; de la Torre-Rodríguez, M.; de Wit, P. TSO_DSO Report, An Integrated Approach to Active System Management with The Focus on TSO-DSO Coordination in Congestion Management and Balancing. ENTSO-E, EDSO, EURELECTRIC, CEDEC, GEODE. 2019. Available online: https:/ / docstore.entsoe.eu/Documents /Publications /Position\%20papers\%20and\%20reports/TSO-DSO_ASM_2019_1 90416.pdf (accessed on 15 February 2021).

9. Alvarez-Perez, M.A. Distribution Network Planning Considering Capacity Mechanisms and Flexibility. Ph.D. Thesis, Luleå University of Technology, Lulea, Sweden, 2019. Available online: http://www.diva-portal.org/smash/get/diva2:1283534/ FULLTEXT01.pdf (accessed on 2 December 2020).

10. European Union. Regulation 2019/943/EU of the European Parliament and of the Council of 5 June 2019 on the Internal Market for Electricity; European Union: Brussels, Belgium, 2019.

11. European Union. Directive 2019/944/EU of the European Parliament and of the Council of 5 June 2019 on Common Rules for the Internal Market for Electricity and Amending Directive 2012/27/EU; European Union: Brussels, Belgium, 2019.

12. Savvopoulos, N.; Konstantinou, T.; Hatziargyriou, N. TSO-DSO Coordination in Decentralized Ancillary Services Markets. In Proceedings of the 2nd International Conference on Smart Energy Systems and Technologies—SEST 2019, Porto, Portugal, 9-11 September 2019.

13. Strbac, G.; Pudjianto, D.; Aunedi, M.; Papadaskalopoulos, D.; Djapic, P.; Ye, Y.; Moreira, R.; Karimi, H.; Fan, Y. Cost-Effective Decarbonization in a Decentralized Market. IEEE PES Power Energy Mag. 2019, 17, 25-36. [CrossRef]

14. Ellis, P.; Hubbard, J. Flexibility Trading Platform-Using Blockchain to Create the Most Efficient Demand-side Response Trading Market. In Transforming Climate Finance and Green Investment with Blockchains, 1st ed.; Marke, A., Ed.; Elsevier: Amsterdam, The Netherlands, 2018; pp. 99-109. [CrossRef]

15. Oureilidis, K.; Malamaki, K.-N.; Gallos, K.; Tsitsimelis, A.; Dikaiakos, C.; Gkavanoudis, S.; Cvetkovic, M.; Mauricio, J.M.; Maza Ortega, J.M.M.; Ramos, J.L.; et al. Ancillary Services Market Design in Distribution Networks: Review and Identification of Barriers. Energies 2020, 13, 917. [CrossRef]

16. Laaksonen, H.; Hovila, P. FlexZone Concept to Enable Resilient Distribution Grid-Possibilities in Sundom Smart Grid. In Proceedings of the CIRED Workshop 2016, Helsinki, Finland, 14-15 June 2016.

17. Panteli, M.; Mancarella, P.; Trakas, D.N.; Kyriakides, E.; Hatziargyriou, N.D. Metrics and quantification of operational and infrastructure resilience in power systems. IEEE Trans. Power Syst. 2017, 32, 4732-4742. [CrossRef]

18. Flexibilize Combined Cycle Powerplant through Power-to-X Solutions Using Non-Conventional Fuels, FLEXnCONFU-Project. Available online: https: / / flexnconfu.eu/. (accessed on 22 February 2021).

19. Skov, I.R.; Schneider, N.; Schweiger, G.; Schöggl, J.-P.; Posch, A. Power-to-X in Denmark: An Analysis of Strengths, Weaknesses, Opportunities and Threats. Energies 2021, 14, 913. [CrossRef]

20. Shayeghi, H.; Shahryari, E.; Moradzadeh, M.; Siano, P. A Survey on Microgrid Energy Management Considering Flexible Energy Sources. Energies 2019, 12, 2156. [CrossRef]

21. Dubey, A.; Bose, A.; Liu, M.; Nando Ochoa, L. Paving the Way for Advanced Distribution Management Systems Applications: Making the Most of Models and Data. IEEE Power Energy Mag. 2020, 18, 63-75. [CrossRef]

22. Minniti, S.; Haque, N.; Nguyen, P.; Pemen, G. Local Markets for Flexibility Trading: Key Stages and Enablers. Energies 2018, 11, 3074. [CrossRef]

23. Olivella-Rosell, P.; Lloret-Gallego, P.; Munné-Collado, Í.; Villafafila-Robles, R.; Sumper, A.; Ødegaard Ottessen, S.; Rajasekharan, J.; Bremdal, B.A. Local Flexibility Market Design for Aggregators Providing Multiple Flexibility Services at Distribution Network Level. Energies 2018, 11, 822. [CrossRef]

24. Smart Energy Europe. Design Principles for (Local) Markets for Electricity System Services, SmartEn Position Paper. 2019. Available online: https:/ / www.smarten.eu/wp-content/uploads/2019/09/20190903-smartEn-Flexibility-Markets-PositionPaper-Final.pdf (accessed on 8 February 2021).

25. Laaksonen, H.; Parthasarathy, C.; Hossein, H.; Shafie-khah, M.; Khajeh, H. Control and Management of Distribution Networks with Flexible Energy Resources. Int. Rev. Electr. Eng. 2020, 15, 213-223. [CrossRef] 
26. Marcello, F.; Pilloni, V.; Giusto, D. Sensor-Based Early Activity Recognition Inside Buildings to Support Energy and Comfort Management Systems. Energies 2019, 12, 2631. [CrossRef]

27. Kumar, J.; Parthasarathy, C.; Västi, M.; Laaksonen, H.; Shafie-khah, M.; Kauhaniemi, K. Sizing and Allocation of Battery Energy Storage Systems in Åland Islands for Large-scale Integration of Renewables and Electric Ferry Charging Stations. Energies 2020, 13, 317. [CrossRef]

28. Zhang, S.; May, D.; Atrazhev, P.; Gul, M.; Musilek, P. Flexibility Platform for Community Energy Systems. In Proceedings of the CIRED 2020 Workshop, Berlin, Germany, 22-23 September 2020.

29. Cejka, S.; Einfalt, A.; Poplavskaya, K.; Stefan, M.; Zeilinger, F. Planning and operating future energy communities. In Proceedings of the CIRED 2020 Workshop, Berlin, Germany, 22-23 September 2020.

30. Leclercq, G.; Ulaganathan, S.; Cambier, G.; Halkin, D.; Tordeur, P.; Maricq, J. Implicit flexibility: Apply smart dynamic pricing using machine learning for different needs. In Proceedings of the CIRED 2020 Workshop, Berlin, Germany, 22-23 September 2020.

31. Van Der Mei, A.J.; Doomernik, J.-P. Perfect Storm for Monopoly Grids II: The Dual Disruptive Impact of Distributed Generation and Local Competition. In Proceedings of the CIRED 2020 Workshop, Berlin, Germany, 22-23 September 2020.

32. Polgári, B.; Sütô, B.; Divényi, D.; Sőrés, P.M.; Vokony, I.; Hartmann, B. Local Electricity Market Design for Peer-to-peer Transactions with Dynamic Grid Usage Pricing. In Proceedings of the CIRED 2020 Workshop, Berlin, Germany, 22-23 September 2020.

33. Grøttum, H.H.; Bjerland, S.F.; del Granado, P.C.; Egging, R. Modelling TSO-DSO coordination: The value of distributed flexible resources to the power system. In Proceedings of the 2019 16th International Conference on the European Energy Market (EEM), Ljubljana, Slovenia, 18-20 September 2019.

34. Simão, T.; Pestana, R.; Reis, F.; Mann, P.; Gaumnitz, F.; Moser, A.; Schittekatte, T. INTERRFACE: TSO-DSO-Consumer interface for innovative grid services-Analysis of end users' requirements, tools and services, market platforms and regulation. In Proceedings of the CIRED 2020 Workshop, Berlin, Germany, 22-23 September 2020.

35. Gürses-Tran, G.; Monti, A.; Vanschoenwinkel, J.; Kessels, K.; Chaves-Ávila, J.P.; Lind, L. Business Use Case Development for TSO-DSO Interoperable Platforms in Large-Scale Demonstrations. In Proceedings of the CIRED 2020 Workshop, Berlin, Germany, 22-23 September 2020.

36. Marten, F.; Hammermeister, I.; Suljanovic, N.; Souvent, A.; Petrovic, N.; Stopar, R.; Lambert, E.; Braun, M. Demonstrations of future TSO-DSO data exchanges with ECCo SP in the EU-project "TDX-ASSIST". In Proceedings of the CIRED 2020 Workshop, Berlin, Germany, 22-23 September 2020.

37. Chang, H.; Moser, A. Benefits of Combined Flexibility Utilization between TSO and DSO for Congestion Management. In Proceedings of the CIRED 2020 Workshop, Berlin, Germany, 22-23 September 2020.

38. Ruwaida, Y.; Etherden, N.; Damsgaard, N.; Isendahl, C. Initial experience from the first CoordiNet demonstration. In Proceedings of the CIRED 2020 Workshop, Berlin, Germany, 22-23 September 2020.

39. Stock, D.S.; Löwer, L.; Harms, Y.; Wende-von Berg, S.; Braun, M.; Wang, Z.; Albers, W.; Calpe, C.; Staudt, M.; Silva, B.; et al. Operational optimization framework improving DSO/TSO coordination demonstrated in real network operation. In Proceedings of the CIRED 2020 Workshop, Berlin, Germany, 22-23 September 2020.

40. Majumdar, A.; Dimitrakopoulos, S.; Alizadeh-Mousavi, O. Grid Monitoring for Efficient Flexibility Provision in Distribution Grids. In Proceedings of the CIRED 2020 Workshop, Berlin, Germany, 22-23 September 2020.

41. Henselmeyer, S.; Weber, S.; Saussenthaler, J. Siemens Active Network Management in Look-ahead Mode for the Enera Region. In Proceedings of the CIRED 2020 Workshop, Berlin, Germany, 22-23 September 2020.

42. Richaud, L.; Marinšek, Z.; Kokos, I.; da Silva, N.P.; Deschamps, P.; Clémence, M.; Benoit, C. Implementation of Local Flexibility Market for Solving Network Issues. In Proceedings of the CIRED 2020 Workshop, Berlin, Germany, 22-23 September 2020.

43. Flexibility from Residential Power Consumption: A New Market Filled with Opportunities, Final Project Report. 2016. Available online: https:/ / www.usef.energy/app/uploads/2016/12/EnergieKoplopersEngels_FinalReport_2016_vs4-1.pdf (accessed on 27 February 2021).

44. Aigner, C.; Witzmann, R. Effectivity of Active Voltage Control Concepts in Distribution Grids. In Proceedings of the 25th International Conference on Electricity Distribution CIRED 2019, Madrid, Spain, 3-6 June 2019.

45. Kaloudas, C.G.; Ochoa, L.F.; Marshall, B.; Majithia, S. Assessing the Future Trends of Reactive Power Demand of Distribution Networks. IEEE Trans. Power Syst. 2017, 32, 4278-4288. [CrossRef]

46. Ahmadi, H.; Akbari Foroud, A. Improvement of the simultaneous active and reactive power markets pricing and structure. IET Gener. Transm. Distrib. 2016, 10, 81-92. [CrossRef]

47. Takala, S.; Pihkala, A.; Heine, P. Control of Reactive Power in Electricity Distribution Companies. In Proceedings of the 25th International Conference on Electricity Distribution CIRED 2019, Madrid, Spain, 3-6 June 2019.

48. Davarzani, S.; Ahmadi, A.R.; Manandhar, T.; Shaw, R.; Georgiopoulos, S.; Martinez, I.; Stojkovska, B. Coordination Trial of Novel Distributed Energy Resources Management System to Provide Reactive Power Services to Address Transmission Constraints. In Proceedings of the CIRED 2020 Workshop, Berlin, Germany, 22-23 September 2020.

49. Moreira, J.; Louro, M.; Simões, T.F.; Villar, J.; Fulgêncio, N.; Silva, B.; Retorta, F.; Aguiar, J.; Rezende, I.; Filipe, N.L.; et al. Reactive Power Provision Using Distribution Grid Resources: Flexibility Hub Use Case. In Proceedings of the CIRED 2020 Workshop, Berlin, Germany, 22-23 September 2020.

50. Wild, J.; Pampliega, D.; Ramos, F.; Le Quellec, P.-J.; Prashar, A.; Richaud, L. Flexibility Platform and Associated Role of Future DSO within Ielectrix Shakti Pilot Project. In Proceedings of the CIRED 2020 Workshop, Berlin, Germany, 22-23 September 2020. 
51. Benzarti, A.; Wellssow, W.H. Control of Distributed Loads and Storage Units-A Novel Approach to Provide Flexibility to the Grid and the Market. In Proceedings of the CIRED 2020 Workshop, Berlin, Germany, 22-23 September 2020.

52. Simão, T.; Terras, J.M.; Gouveia, C.; Gerard, H.; Meeus, L.; Calpe, C.; Slawomir, N.; Otuszewski, T.; Arín, R.C.; Gonzalez, F. EUniversal: The Universal Market Enabling Interface (UMEI) as a way to unlock flexibility solutions for cost-effective management of smarter distribution grids. In Proceedings of the CIRED 2020 Workshop, Berlin, Germany, 22-23 September 2020.

53. Blanquet, A.; Santo, B.E.; Basílio, J.; Pratas, A.; Guerreiro, M.; Gouveia, C.; Rua, D.; Bessa, R.; Carrapatoso, A.; Alves, E.; et al. Challenging an IoT Platform to address New Services in a Flexible Grid. In Proceedings of the CIRED 2020 Workshop, Berlin, Germany, 22-23 September 2020.

54. Köppl, S.; Estermann, T.; Springmann, E.; Hofer, R. Smart Market Platform as a Coordination Mechanism of Distributed Flexibility for Congestion Management. In Proceedings of the CIRED 2020 Workshop, Berlin, Germany, 22-23 September 2020.

55. Dronne, T.; Roques, F.; Saguan, M. Local flexibility market: Which design for which needs? In Proceedings of the CIRED 2020 Workshop, Berlin, Germany, 22-23 September 2020.

56. Exner, C.; Frankenbach, M.-A.; von Haken, A.; Höck, A.; Konermann, M. A Practical Implementation of the Management of Local Flexible Generation and Consumption Units Using a Quota-based Grid Traffic Light Approach. In Proceedings of the CIRED 2020 Workshop, Berlin, Germany, 22-23 September 2020.

57. Bertetti, O.; Ahmadi, A.R.; Manandhar, T.; Sokari-Briggs, T.; Walsh, H.; Davarzani, S.; Georgiopoulos, S.; White, M. UK Power Networks Launches Major Flexible Distributed Generation Rollout Program with Advanced ANM System. In Proceedings of the CIRED 2020 Workshop, Berlin, Germany, 22-23 September 2020.

58. Corsetti, E.; del Corno, A.; Riello, M. A Methodology to Support the Flexibility Maximization for Multi-Energy Systems to Provide Services to the Electrical Distribution System. In Proceedings of the CIRED 2020 Workshop, Berlin, Germany, 22-23 September 2020.

59. Oprea, S.-V.; Bara, A. Machine Learning Algorithms for Short-Term Load Forecast in Residential Buildings Using Smart Meters, Sensors and Big Data Solutions. IEEE Access 2019, 7, 177874-177889. [CrossRef]

60. Gonçalves, R.; Soares, T.; Louro, M.; Ferreira, L.A.F.M.; Carvalho, P.M.S.; Carvalho, F.; Machado, J. Dynamic Reactive Power Management based on Forecasts and Chronological Power Flow. In Proceedings of the CIRED 2020 Workshop, Berlin, Germany, 22-23 September 2020.

61. Weber, J.; Zdrallek, M.; Abele, H.; Brenneisen, O.; Mogel, M. Estimating the Reactive Power Potential of Distribution Networks. In Proceedings of the CIRED 2020 Workshop, Berlin, Germany, 22-23 September 2020.

62. Schroeder, H.; Hobert, A.; Zdrallek, M.; Seeger, L.; Backhaus, C.; Biesenbach, P. Evaluation of a Forecast Model to Predict Electricity Demand Profiles of Urban Households Considering Dynamic Incentives. In Proceedings of the CIRED 2020 Workshop, Berlin, Germany, 22-23 September 2020.

63. Renjit, A.; Weng, D.; Hubert, T.; Seal, B. DERMS Reference Control Methods for DER Group Management. In Proceedings of the 25th International Conference on Electricity Distribution CIRED 2019, Madrid, Spain, 3-6 June 2019.

64. Reilly, J.; Joos, G. Integration and Aggregation of Distributed Energy Resources-Operating Approaches, Standards and Guidelines. In Proceedings of the 25th International Conference on Electricity Distribution CIRED 2019, Madrid, Spain, 3-6 June 2019.

65. Lambert, E.; Morais, H.; Reis, F.; Alves, R.; Taylor, G.; Souvent, A.; Suljanovic, N. Practices and architectures for TSO-DSO data exchange: European landscape. In Proceedings of the 8th IEEE PES Innovative Smart Grid Technologies Conference Europe ISGT Europe 2018, Sarajevo, Bosnia and Herzegovina, 21-25 October 2018.

66. Maitra, A.; Singh, G.; Pratt, A.; Jecu, C. Microgrid Controller and Distributed Energy Resource Functionality Verification via Laboratory and Field Verification. In Proceedings of the 25th International Conference on Electricity Distribution CIRED 2019, Madrid, Spain, 3-6 June 2019.

67. Astapov, V.; Divshali, P.H.; Söder, L. The Potential of Distribution Grid as an Alternative Source for Reactive Power Control in Transmission Grid. In Proceedings of the 20th European Conference on Power Electronics and Applications-EPE 2018, Riga, Latvia, 17-21 September 2018.

68. Hafezi, H.; Laaksonen, H. Autonomous Soft Open Point Control for Active Distribution Network Voltage Level Management. In Proceedings of the 13th IEEE PowerTech 2019, Milan, Italy, 23-27 June 2019.

69. Hes, S.; Kula, J.; Svec, J. Technical Solutions for Increasing DER Hosting Capacity in Distribution Grids in The Czech Republic in Terms of European Project INTERFLEX. In Proceedings of the 25th International Conference on Electricity Distribution CIRED 2019, Madrid, Spain, 3-6 June 2019.

70. Ulasenka, A.; del Rio-Etayo, L.; Cirujano, P.; Ortiz, A.; Brandl, R.; Montoya, J. Holistic Coordination of Smart Technologies for Efficient LV Operation, Increasing Hosting Capacity and Reducing Grid Losses. In Proceedings of the 25th International Conference on Electricity Distribution CIRED 2019, Madrid, Spain, 3-6 June 2019.

71. Wang, Y.; Xu, Y.; Tang, Y.; Syed, M.H.; Guillo-Sansano, E.; Burt, G.M. Decentralized-Distributed Hybrid Voltage Regulation of Power Distribution Networks Based on Power Inverters. IET Gener. Transm. Distrib. 2019, 13, 444-451. [CrossRef]

72. Divshali, P.H.; Söder, L. Improving Hosting Capacity of Rooftop PVs by Quadratic Control of an LV Central BSS. IEEE Trans. Smart Grid 2017, 10, 919-927. [CrossRef]

73. Laaksonen, H. Securing Passive Islanding Detection and Enabling Stable Islanding with Q/f-droop Control of DG Unit. Int. Rev. Electr. Eng. 2014, 9, 592-602. 
74. Mutanen, A.; Järventausta, P.; Repo, S. Smart Meter Data-Based Load Profiles and Their Effect on Distribution System State Estimation Accuracy. Int. Rev. Electr. Eng. 2017, 12, 460-469. [CrossRef]

75. Alahäivälä, A.; Saarijärvi, E.; Lehtonen, M. Modeling Electric Vehicle Charging Flexibility for the Maintaining of Power Balance. Int. Rev. Electr. Eng. 2013, 8, 1759-1770.

76. Alahäivälä, A.; Nikkilä, R.; Lehtonen, M. Comparison of Electric Vehicle Charging Control Strategies for the Power System Primary Control. Int. Rev. Electr. Eng. 2013, 8, 1057-1066.

77. Annathurai, V.; Gan, C.K.; Ibrahim, K.A.; Baharin, K.A.; Ghani, M.R. A Review on the Impact of Distributed Energy Resources Uncertainty on Distribution Networks. Int. Rev. Electr. Eng. 2016, 11, 420-427. [CrossRef]

78. Adiguno, F.K.; Mai, T.T.; Nguyen, P.H. Mitigating Impact of Large-Scale PV Integration on MV Distribution Network with Sequential Control Functions: A Case Study in Noordwolde Grid, The Netherlands. In Proceedings of the 25th International Conference on Electricity Distribution CIRED 2019, Madrid, Spain, 3-6 June 2019.

79. Nguyen, H.X.; Tsuji, T. Voltage Violation Mitigation by Adaptive Droop Control of PV Inverter in Medium-Voltage Network. In Proceedings of the 8th IEEE PES Innovative Smart Grid Technologies Conference Europe ISGT Europe 2018, Sarajevo, Bosnia and Herzegovina, 21-25 October 2018.

80. Laaksonen, H.; Sirviö, K.; Aflecht, S.; Hovila, P. Multi-Objective Active Network Management Scheme Studied in Sundom Smart Grid with MV and LV Network Connected DER Units. In Proceedings of the 25th International Conference on Electricity Distribution CIRED 2019, Madrid, Spain, 3-6 June 2019.

81. Laaksonen, H.; Parthasarathy, C.; Hafezi, H.; Shafie-khah, M.; Khajeh, H.; Hatziargyriou, N. Solutions to Increase PV Hosting Capacity and Provision of Services from Flexible Energy Resources. Appl. Sci. 2020, 10, 5146. [CrossRef]

82. Petrou, K.; Liu, M.Z.; Procopiou, A.T.; Ochoa, L.F.; Theunissen, J.; Harding, J. Managing Residential Prosumers using Operating Envelopes: An Australian Case Study. In Proceedings of the CIRED 2020 Workshop, Berlin, Germany, 22-23 September 2020.

83. Ela, E.; Billimoria, F.; Ragsdale, K.; Moorty, S.; O’Sullivan, J.; Gramlich, R.; Rothleder, M.; Rew, B.; Supponen, M.; Sotkiewicz, P. Future Electricity Markets: Designing for Massive Amounts of Zero-Variable-Cost Renewable Resources. IEEE PES Power Energy Mag. 2019, 17, 58-66. [CrossRef]

84. Rossi, J.; Srivastava, A.; Steen, D.; Tuan, L.A. A Study of the European Regulatory Framework for Smart Grid Solutions in Future Distribution Systems. In Proceedings of the CIRED 2020 Workshop, Berlin, Germany, 22-23 September 2020.

85. Equigy Crowd Balancing Platform. Available online: https:// equigy.com/ (accessed on 17 February 2021).

86. NODES Independent Marketplace. Available online: https://nodesmarket.com/ (accessed on 15 February 2021).

87. Sarti, R. NODES White Paper: Paving the Way for Flexibility. October 2020. Available online: https://nodesmarket.com/ download / paving-the-way-for-flexibility-nodes-market-design-2020/ (accessed on 15 February 2021).

88. FLEXIMAR-Novel Marketplace for Energy Flexibility. Available online: https:/ / fleximarex.com/ (accessed on 19 February 2021).

89. Sharma, D.; Rehu, J.; Känsälä, K.; Ailisto, H. An Automatic Aggregator of Power Flexibility in Smart Buildings Using Software Based Orchestration. Sensors 2021, 21, 867. [CrossRef] [PubMed]

90. Ran, B.; Wijbrandi, W.; Laarakkers, J.; Nutma, J.; Klever, M. Maximizing the utilization of DERs with the Interflex Aggregation Platform for Flexibility. In Proceedings of the 25th International Conference on Electricity Distribution CIRED 2019, Madrid, Spain, 3-6 June 2019.

91. Ahmadi, A.R.; Martinez, I.; Stojkovska, B.; Shaw, R.; Manandhar, T.; Georgiopoulos, S. UK Power Networks Providing Power Services from Distributed Energy Resources to Transmission System Via A Centralised DERMS Platform. In Proceedings of the 25th International Conference on Electricity Distribution CIRED 2019, Madrid, Spain, 3-6 June 2019.

92. Ahmadi, A.R.; Gordon, M.; White, M.; Stamatiadis, D.; Minton, A.; Georgiopoulos, S. Enhanced Transmission and Distribution System Coordination and Control Utilising Distribution Network Capacity and Avoiding Conflicts of Service Offered to Transmission System Operator. In Proceedings of the 25th International Conference on Electricity Distribution CIRED 2019, Madrid, Spain, 3-6 June 2019.

93. Vasconcelos, M.; Cramer, W.; Jessenberger, S.; Amthor, A.; Ziegler, C.; Schmitt, C.; Heringer, F.; Armstorfer, A. The Pebbless Project-Enabling Blockchain-based Transactive Energy Trading of Energy \& Flexibility within A Regional Market. In Proceedings of the 25th International Conference on Electricity Distribution CIRED 2019, Madrid, Spain, 3-6 June 2019.

94. Surmann, A.; Chantrel, S.P.M.; Fischer, D.; Kohrs, R.; Wittwer, C. Stochastic Bottom-up Framework for Load and Flexibility for Agent Based Controls of Energy Communities. In Proceedings of the 25th International Conference on Electricity Distribution CIRED 2019, Madrid, Spain, 3-6 June 2019.

95. Brenzikofer, A.; Meuw, A.; Schopfer, S.; Wörner, A.; Dürr, C. Quartierstrom: A Decentralized Local P2P Energy Market Pilot on A Self-governed Blockchain. In Proceedings of the 25th International Conference on Electricity Distribution CIRED 2019, Madrid, Spain, 3-6 June 2019.

96. Pop, C.; Cioara, T.; Antal, M.; Anghel, I.; Salomie, I.; Bertoncini, M. Blockchain Based Decentralized Management of Demand Response Programs in Smart Energy Grids. Sensors 2018, 18, 162. [CrossRef] [PubMed]

97. Losa, I.; Monti, A.; Croce, V.; de Luca, E.; Stratogiannis, D.; Petters, B. Innovative solutions to enable flexibility and retail markets in distribution grids: The Platone approach. In Proceedings of the CIRED 2020 Workshop, Berlin, Germany, 22-23 September 2020. 
98. Schreck, S.; Thiem, S.; Amthor, A.; Metzger, M.; Niessen, S. Activating Current and Future Flexibility Potential in the Distribution Grid through Local Energy Markets. In Proceedings of the CIRED 2020 Workshop, Berlin, Germany, 22-23 September 2020.

99. Moreira, J.; Bernardo, R.; Prata, R.; Krisper, U.; Bessa, R.; Coelho, F.; Schwarzländer, F. A Service Catalyst Providing a Neutral Framework for Supporting Grid Operation, while Promoting Market-based Services: Grid and Market Hub. In Proceedings of the CIRED 2020 Workshop, Berlin, Germany, 22-23 September 2020.

100. Merckx, K.; Rosen, A.; Métivier, N. Market Clearing Algorithm, A Key Enabler of Market-based Flexibility Mechanism at Distribution Level. In Proceedings of the CIRED 2020 Workshop, Berlin, Germany, 22-23 September 2020.

101. Alcarria, R.; Bordel, B.; Robles, T.; Martín, D.; Manso-Callejo, M.-Á. A Blockchain-Based Authorization System for Trustworthy Resource Monitoring and Trading in Smart Communities. Sensors 2018, 18, 3561. [CrossRef]

102. Mezquita, Y.; Gazafroudi, A.S.; Kamišalić, A.; Shafie-Khah, M.; Laaksonen, H.; Corchado, J. Multi-Agent Architecture for Peer-toPeer Electricity Trading based on Blockchain Technology. In Proceedings of the 27th International Conference on Information, Communication and Automation Technologies-ICAT 2019, Sarajevo, Bosnia and Herzegovina, 20-23 October 2019.

103. Guerrero, J.; Chapman, A.C.; Verbic, G. Decentralized P2P Energy Trading Under Network Constraints in a Low-Voltage Network. IEEE Trans. Smart Grid 2019, 10, 5163-5173. [CrossRef]

104. Abdella, J.; Shuaib, K. Peer to Peer Distributed Energy Trading in Smart Grids: A Survey. Energies 2018, 11, 1560. [CrossRef]

105. Barooah, P. Coordinating of Energy Storage and Flexible Demand Resources; IEEE Smart Grid: Piscataway, NJ, USA, 2019.

106. Strbac, G.; Papadaskalopoulos, D.; Chrysanthopoulos, N.; Estanqueiro, A.; Algarvio, H.; Lopes, F.; de Vries, L.; Morales-España, G.; Sijm, J.; Hernandez-Serna, R.; et al. Decarbonization of Electricity Systems in Europe: Market Design Challenges. IEEE Power Energy Mag. 2021, 19, 53-63. [CrossRef]

107. Ostergaard, J.; Ziras, C.; Bindner, H.W.; Kazempour, J.; Marinelli, M.; Markussen, P.; Horn Rosted, S.; Christensen, J.S. Energy Security Through Demand-Side Flexibility: The Case of Denmark. IEEE Power Energy Mag. 2021, 19, 6-55. [CrossRef]

108. Samani, A.E.; D'Amicis, A.; de Kooning, J.D.M.; Bozalakov, D.; Silva, P.; Vandevelde, L. Grid balancing with a large-scale electrolyser providing primary reserve. IET Renew. Power Gener. 2020, 14, 3070-3078. [CrossRef]

109. Ghazavi-Dozein, M.; Jalali, A.; Mancarella, P. Fast Frequency Response from Utility-Scale Hydrogen Electrolyzers. IEEE Trans. Sustain. Energy 2021. [CrossRef]

110. Jiang, Y.; Mei, F.; Lu, J.; Lu, J. Two-Stage Joint Optimal Scheduling of a Distribution Network with Integrated Energy Systems. IEEE Access 2021, 9, 12555-12566. [CrossRef] 